Published in final edited form as:

Cancer Metastasis Rev. 2011 December ; 30(0): 525-540. doi:10.1007/s10555-011-9315-y.

\title{
EET signaling in cancer
}

Dipak Panigrahy,

Vascular Biology Program, Boston Children's Hospital, Division of Pediatric Oncology, Dana-

Farber Cancer Institute, Harvard Medical School, Boston, MA, USA

Emily R. Greene,

Vascular Biology Program, Boston Children's Hospital, Division of Pediatric Oncology, Dana-

Farber Cancer Institute, Harvard Medical School, Boston, MA, USA

Ambra Pozzi,

Department of Medicine and Cancer Biology, Division of Nephrology and Hypertension, Vanderbilt University, Nashville, TN, USA

Dao Wen Wang, and

Department of Internal Medicine and Gene Therapy Center, Tongji Hospital, Tongji Medical

College, Huazhong University of Science and Technology, Wuhan 430030, People's Republic of

China

\section{Darryl C. Zeldin}

Division of Intramural Research, National Institute of Environmental Health Science, National Institute of Health, Research Triangle Park, NC, USA

Dipak Panigrahy: dipak.panigrahy@childrens.harvard.edu; Emily R. Greene: emily.greene@childrens.harvard.edu; Ambra Pozzi: ambra.pozzi@vanderbilt.edu; Dao Wen Wang: dwwang@tjh.tjmu.edu.cn; Darryl C. Zeldin: zeldin@niehs.nih.gov

\section{Abstract}

Inflammation and angiogenesis in the tumor microenvironment are increasingly implicated in tumorigenesis. Endogenously produced lipid autacoids, locally acting small-molecule mediators, play a central role in inflammation and tissue homeostasis. These lipid mediators, collectively referred to as eicosanoids, have recently been implicated in cancer. Although eicosanoids, including prostaglandins and leukotrienes, are best known as products of arachidonic acid metabolism by cyclooxygenases and lipoxygenases, arachidonic acid is also a substrate for another enzymatic pathway, the cytochrome P450 (CYP) system. This eicosanoid pathway consists of two main branches: $\omega$-hydroxylases which converts arachidonic acid to hydroxyeicosatetraenoic acids (HETEs) and epoxygenases which converts it to four regioisomeric epoxyeicosatrienoic acids (EETs; 5,6-EET, 8,9-EET, 11,12-EET, and 14,15-EET). EETs regulate inflammation and vascular tone. The bioactive EETs are produced predominantly in the endothelium and are mainly metabolized by soluble epoxide hydrolase to less active dihydroxyeicosatrienoic acids. EET signaling was originally studied in conjunction with inflammatory and cardiovascular disease. Arachidonic acid and its metabolites have recently stimulated great interest in cancer biology. To date, most research on eicosanoids in cancer has focused on the COX and LOX pathways. In contrast, the role of cytochrome P450-derived eicosanoids, such as EETs and HETEs, in cancer has received little attention. While CYP epoxygenases are expressed in human cancers and promote human cancer metastasis, the role of EETs (the direct products of CYP epoxygenases) in cancer remains poorly characterized. In this review, the emerging role of EET signaling in angiogenesis, inflammation, and cancer is discussed.

(C) Springer Science+Business Media, LLC 2011

Correspondence to: Darryl C. Zeldin, zeldin@niehs.nih.gov. 


\section{Keywords}

Cytochrome P450 epoxygenase; EETs; Cancer; Metastasis; Arachidonic acid

\section{Introduction}

Arachidonic acid and its metabolites have recently attracted significant attention due to increasing evidence of their role in cancer biology $[1,2]$. Products of arachidonic acid metabolism, including prostaglandins, leukotrienes, lipoxins, and cytochrome P450 (CYP)derived metabolites, are potent mediators of inflammation $[3,4]$. These endogenously produced lipid autacoids are locally acting small-molecule mediators that play a central role in tissue homeostasis. These lipid mediators are collectively referred to as eicosanoids. Arachidonic acid is converted to eicosanoids by the distinct enzyme systems: cyclooxygenases (COX-1 and COX-2), lipoxygenases (5-LOX, 12-LOX, 15-LOXa, 15LOXb), and cytochrome P450s ( $\omega$-hydroxylases and epoxygenases). These enzymes are the target of approved drugs for the treatment of pain, inflammation, asthma, and allergies [5]. The arachidonic acid pathways, including cytochrome P450-derived eicosanoids, were originally studied for their role in inflammatory and cardiovascular function rather than cancer pathways $[3,5-8]$.

The epoxygenases comprise a superfamily of microsomal CYP enzymes expressed in the liver, kidney, and the cardiovascular system. Epoxyeicosatrienoic acid (EETs) are generated via the conversion of arachidonic acid by CYP epoxygenases and are mainly metabolized by soluble epoxide hydrolase (sEH). EETs are lipid signaling molecules which act as autocrine and paracrine mediators of physiological processes such as proliferation, migration, and inflammation in several tissues (Fig. 1) [8, 9]. EETs are quickly metabolized in most tissues, making studying these particular lipid mediators challenging [10]. The CYP pathway is particularly relevant in tissues that express low cyclooxygenase (COX) and lipoxygenase (LOX) activities. CYP enzymes convert arachidonic acid to hydroxyeicosatetraenoic acids (HETEs) or EETs. The role of cytochrome P450-derived eicosanoids, such as EETs, in cancer has been largely neglected [11]. The initial pioneering studies demonstrating that CYP epoxygenases can promote cancer growth and metastasis have been led by the Wang laboratory [12,13]. Further studies by Pozzi et al. [14-16] have demonstrated that PPARa ligands downregulate CYP expoxygenases and reduce EETs, thereby inhibiting tumor angiogenesis in rodent models. EETs have been found in endothelial cells and stimulate angiogenesis [17-19]. EET biosynthesis and actions can also be directly influenced by nutrients and inflammatory processes [20]. Despite many studies characterizing the proangiogenic and anti-inflammatory signaling pathways of EETs, the signaling pathways of EETs in cancer biology remains poorly characterized [11].

\subsection{Overview of the CYP pathway}

The CYP-dependent metabolism of arachidonic acid occurs in several tissues including the liver, kidney, and the cardiovascular system. The CYP enzymes relevant to arachidonic acid metabolism include two distinct pathways: the $\omega$-hydroxylases and epoxygenases. The $\omega-$ hydroxylases of the 4A and 4F gene families of cytochrome P450 (CYP4A and CYP4F) convert arachidonic acid to autacoids such as HETEs. 20-Hydroxyeicosatetraenoic acid (20HETE) is the principal isoform of this pathway and has shown vasocon-striction activity [21-23]. CYP epoxygenases are encoded predominantly by the CYP2C and CYP2J genes and generate EETs, which have demonstrated vasodilatory and anti-inflammatory activities $[3,24,25]$. EETs are then further metabolized, mainly by $\mathrm{sEH}$, to dihydroxyeicosatrienoic acids (DHETs) that have traditionally been considered to be less active than EETs [26, 27]. 
The biology of both the CYP epoxygenases and $\omega$-hydroxylases has been extensively reviewed [3, 5-8].

CYP2C enzymes are induced by hypoxia, and it is believed that endothelial cells are the major source of EETs during inflammation and angiogenesis. Thus, EETs may act in an autocrine fashion on the endothelium. EETs induce vasodilatory and anti-inflammatory effects in blood vessels, are beneficial in lowering blood pressure, and protect the myocardium and brain from ischemia [3, 28]. Targeted inhibition of the EET-metabolizing enzyme sEH raises the levels of cardioprotective EETs. Thus, sEH inhibitors are being evaluated in clinical trials for hypertension [5].

\subsection{History of the CYP eicosanoids}

Based on the pioneering work of Estabrook, both Capdevila and Falck founded and characterized another pathway, microsomal cytochrome $\mathrm{P} 450$ arachidonic acid metabolism [29, 30]. In 1981, metabolites, separate from the prosta-noids and leukotrienes, were identified by the oxidative metabolism of arachidonic acid by microsomal cytochrome P450 systems [31-34]. In 1996, EETs were identified by Campbell et al. [35] as endotheliumderived substances that hyperpolarize vascular smooth muscle. Following this, Zeldin et al. $[26,36]$ were the first to clone and identify CYP2J2, which helped create the tools needed to further characterize EETs, such as CYP2J2 transgenic mice. These discoveries sparked interest in the newly developing field of CYP eicosanoids. Over the past decade, the Falck laboratory has synthesized agonists and antagonists of CYP metabolites, including EETs and 20-HETE. However, the rapid metabolism of EETs and other epoxylipids has made it difficult to study the biological relevance of these metabolites. To address this challenge, the Hammock laboratory pioneered a series of sEH inhibitors that further stabilized EETs [27, 37]. sEH inhibitors, which increase EET levels, have been evaluated in the clinic for cardiovascular diseases, such as hypertension [5].

In this review, we survey the largely unexplored field of EETs as well as 20-HETE in tumorigenesis. We will focus on their roles in cancer as well as in angiogenesis and inflammation. These are two interdependent processes in the tumor microenvironment that play pivotal roles in tumor growth and metastasis.

\section{CYP genes, enzymes, and current role in pharmacology}

This CYP superfamily is a complex group of enzymes that consist of upwards of 102 putatively functional genes in mice and as few as 57 in humans $[38,39]$. These CYP enzymes differ greatly from mouse to man, presenting challenges in the characterization of CYPs in this field [40, 41].

The best-known function of the CYP enzymes is the detoxification of compounds such as anticancer drugs and xenobiotics in the liver. The field of directly targeting cytochrome P450 enzymes in cancer has rapidly expanded. Blocking these enzymes improves the halflife of the cytotoxic drugs-a strategy that is currently under evaluation to improve the efficacy of cancer drug delivery [38, 42, 43]. Conversely, prodrugs activated by CYP enzymes are being used to inhibit tumor growth by targeting the tumor cells and tumorassociated endothelial cells $[44,45]$. Therapeutic success has already been obtained using cytochrome $\mathrm{P} 450$ inhibitors to treat breast cancer [46]. This has prompted investigators to determine whether cytochrome $\mathrm{P} 450$ inhibitors can be utilized to treat other hormonally responsive cancers including prostate cancer [44, 47, 48]. 


\section{Synthesis and degradation of EETs and HETEs}

Arachidonic acid is an essential component of mammalian cell membranes and plays a critical role in the synthesis of bioactive eicosanoids [3]. Eicosanoids are generated via the oxidation of the 20-carbon chain present on arachidonic acid or other related fatty acids [5]. During processes such as inflammation, arachidonic acid is released from the cell membrane through the activation of phospholipase $\mathrm{A}_{2}$ [3]. The epoxygenase CYP enzymes metabolizes arachidonic acid by olefin epoxidation, resulting in four regioisomeric EETs: 5,6-EET, 8,9EET, 11,12-EET, and 14,15-EET [3]. Each regioisomer can be formed as either an R,S or $\mathrm{S}, \mathrm{R}$ enantiomer as the epoxide group can attach at each of the double bonds in two separate configurations, resulting in a total of eight EETs (reviewed by Zeldin) [3]. Arachidonic acid is metabolized by the CYP w-hydroxylases to 7-, 10-, 12-, 13, 15-, 16-, 17-, 18-, 19-, and 20HETEs, the principal metabolite being the pro-inflammatory 20-HETE [6].

EETs are primarily synthesized in endothelial cells which express isoforms of CYP2C and CYP2J (e.g., CYP2C8, CYP2C9, and CYP2J2) [17, 20,24, 49, 50]. EETs are produced in other cell types as well, such as astrocytes and cardiac myocytes [18, 51-54]. Additionally, monocytic leukocytes have recently been shown to express CYP2J2 and therefore may generate EETs [55].

The synthesis of 20-HETE and 12-HETE occurs in vascular smooth muscle cells and fibroblasts, respectively, through the CYP pathways [6, 56]. 20-HETE synthesis can be controlled through a positive feedback mechanism by activating calcium/calmodulindependent protein kinase-induced mitogen-activated protein kinase in smooth muscle cells [57]. This Ras/MAPK pathway then amplifies cytosolic phospholipase $A_{2}$. This mechanism results in the release of additional arachidonic acid substrates that can then be converted to 20-HETE.

Degradation of 20-HETE occurs via multiple pathways. For example, in endothelial cells, 20-HETE can be metabolized by COX to 20-hydroxy prostaglandin $\mathrm{G}_{2}$ and $\mathrm{H}_{2}$ [58]. 20HETE may also be oxidized by $\omega$-oxidation or $\beta$-oxidation [59]. In contrast, the degradation of EETs appears to be more uniform and is exerted mainly by sEH, resulting in DHETs [26, 27]. The synthesis pathways for HETEs and EETs are complex in exhibiting multiple routes leading to the same compound. HETEs can be generated through the distinct arachidonic acid metabolic pathways, COX, LOX, and CYP 450 [60]. While EETs are mainly formed by CYP2C and CYP2J, other EET-producing CYPs such as CYP4X1, CYP3A4, and CYP2U1 have been characterized [25, 61-63]. These cytochrome P450s (CYP4X1 and CYP2U1) metabolize arachidonic acid to 8,9- and 14,15-EETs as well as 19-, and 20-HETE, respectively [62,63].

\section{Targets of EETs}

The molecular mechanism(s) of EETs is poorly understood, but continues to be fiercely studied. A series of agonists have been developed to help characterize the binding and metabolism of 14,15-EET [64]. Recent studies from the Campbell laboratory demonstrated the existence of a high-affinity EET surface-binding protein expressed in cell membranes [65]. While the EET receptor(s) has not yet been identified, intracellular signals by $\mathrm{G}$ protein pathways have been implicated $[5,64,66]$. Over $90 \%$ of circulating EETs are incorporated into the phospholipid bilayer of cell membranes, mainly as low-density lipoproteins [67]. EETs can act as long-chain fatty acids and bind to fatty acid-binding proteins and nuclear peroxisome proliferator-activated receptors (PPARY and PPARa). These actions suggest that an intracellular mechanism occurs in these cells [66, 68-70]. In fact, all four EETs and their metabolites can stimulate PPAR/RXR heterodimer binding to a PPRE [70-74]. 


\section{The role of tumor microenvironment in tumorigenesis: angiogenesis and inflammation}

The tumor microenvironment, including endothelial cells and inflammatory cells, plays a critical role in cancer and may be an ideal target for intervention as demonstrated by the increasing activity of anti-angiogenic and/or antiinflammatory therapy [75-78]. Lipid autacoids can potentially target different cellular components of a tumor. Over the past decade, a paradigm shift has taken place in cancer research. It has become clear that cancer is not just a cell-autonomous disease in which genetic alterations in cancer cells alone confer autonomous proliferation, apoptosis resistance, and invasive capabilities. Now, it is accepted that tumor growth is also a non-cell-autonomous process requiring support from the "tissue microenvironment" in the "tumor bed" [79-81]. Non-cell-autonomous contribution to tumorigenesis from the "host tissue", most clearly epitomized by tumor vasculature, is crucial for tumor expansion and progression [82]. This hypothesis, developed by Folkman in 1971, stated that tumor growth requires neovascularization and that such "tumor angiogenesis" is induced by tumor-derived soluble factors [83]. Since then, the contributions of non-cancerous cells to the growth of tumors have extended beyond endothelial cells to pericytes, inflammatory cells, immune cells, fibroblasts, myofibroblasts, and adipocytes [84]. Non-local cells, including bone marrow-derived macrophages, neutrophils, mast cells, and mesenchymal stem cells are also recruited, contributing to the invasiveness and metastatic ability of neoplastic epithelial cells [85]. Nakayama et al. [55] showed that the expression of CYP2J2 was upregulated when human monocytes differentiated into macrophages and that human monocytic cells and macrophages may metabolize arachidonic acid via CYP expoxygenases.

Both angiogenesis and inflammation are interdependent stromal processes that exert substantial influence on tumor growth and metastasis. Pro-inflammatory enzymes and cytokines act to promote tumor growth by an increased infiltration of macrophages and neutrophils, which in turn may increase angiogenesis and correlate with poor prognosis [86, 87]; in other cases, inflammatory infiltration of lymphocytic/monocytic cells can actually inhibit tumor growth [88]. Conversely, blocking inflammation can be associated with the stimulation of cancer $[1,89,90]$. Both inhibition and activation of the NF-KB protein complex can promote carcinogenesis [91-93]. Inflammation in the tumor bed can then either stimulate or inhibit tumor growth $[90,94,95]$. Thus, pharmacological modulation of inflammation in cancer treatments must be evaluated with the notion that inflammation may be a double-edged sword in this field.

\section{Lipid autacoids in cancer}

It has been recognized that tumor growth is a complex process involving many cell types. The intercellular communication that takes place between these cells is conducted by an array of soluble factors such as proteinaceous growth factors and chemokines, vascular endothelial growth factor (VEGF), FGF 2 , TGF- $\beta$, TNF- $\alpha$, IL-1, and oxygen free radicals [96]. Little attention has been paid to small-molecule mediators such as lipid autacoids, whose role in cancer has only recently emerged. Given that a tumor consists of both cancerous and noncancerous cells, the role of autacoids in tumor growth can be separated by their direct effects on neoplastic growth and their effects on endothelial, inflammatory, and other stromal cells.

The pro-inflammatory prostaglandins and leukotrienes directly induce epithelial tumor cell proliferation, survival, migration, and invasion in an autocrine and paracrine manner [1]. Lipid autacoids, such as $\mathrm{PGE}_{2}$ and $\mathrm{LTB}_{4}$, stimulate both epithelial cells and stromal cells to produce VEGF and FGF-2 (Fig. 2). These angiogenic growth factors induce COX-2, and in 
turn $\mathrm{PGE}_{2}$ and $\mathrm{PGI}_{2}$, in endothelial cells, creating a feedback loop [1,97]. Other studies have linked eicosanoids to stromal inflammation in epithelial ovarian cancer [98]. The levels of eicosanoid metabolites, such as $\mathrm{PGE}_{2}, 5$-HETE, and 12-HETE, increase progressively from patients with benign pelvic disease to those with epithelial ovarian cancer. This demonstrates the involvement of lipid autacoids in the inflammatory environment of cancer [98]. However, the role of lipid autacoids derived from the CYP eicosanoid pathway remains poorly characterized in cancer.

\section{HETEs effects on the vasculature and inflammation}

LOX-derived HETEs inhibit apoptosis, stimulate angiogenesis, and enhance the proliferation and migration of cancer cells [60]. 20-HETE, the principal metabolite of the CYP w-hydroxylation pathway, is a pro-inflammatory mediator that markedly stimulates the production of inflammatory cytokines/chemokines in endothelial cells, including interleukin-8 (IL-8), IL-13, IL-4, and prostaglandin $\mathrm{E}_{2}$ [99]. 20-HETE stimulates the activation of the NF-KB and MAPK/ERK pathways, which suggests that HETE's proinflammatory effect may be mediated by the central inflammatory pathway of NF-KB [99].

In addition to its pro-inflammatory activity, 20-HETE has pro-angiogenic activities including the stimulation of endothelial cell proliferation, migration, and cell survival [100103]. 20-HETE has an important role in VEGF-dependent angiogenesis [104](reviewed in [103]). While VEGF seems to be the primary mediator of 20-HETE-induced endothelial cell proliferation, inhibition with a VEGF antibody does not completely abrogate the mitogenic effect of 20-HETE [100]. This suggests that other pathways are involved in 20-HETEmediated angiogenesis [100].

The pro-angiogenic factor FGF-2 can activate cytosolic phospholipase $\mathrm{A}_{2}$ (the enzyme which releases arachidonic acid from cell membranes) in endothelial cells [105]. Thus, FGF-2 can increase arachidonic acid production, potentially stimulating CYP4A and the production of 20-HETE [103]. Also, the overexpression of CYP4A1, which increases 20HETE production, results in an increased neovessel formation [106].

HET0016, a selective inhibitor of CYP4A, suppresses the formation of 20-HETE at a concentration $<10 \mathrm{nM}$ and has no effect on epoxygenase, cyclooxygenase, or lipoxygenase activity at concentrations up to $1 \mu \mathrm{M}[6,107]$. HET0016 inhibits VEGF-induced endothelial cell proliferation in vitro and corneal neovascularization in vivo when administered locally with pellets containing VEGF [102]. When administered locally into the cornea, HET0016 inhibited tumor-induced (U251 glioblastoma cells) angiogenesis by $70 \%$ [102]. Furthermore, the administration of the stable 20-HETE agonist, 20-hydroxyeicosa-6(Z), 15(Z)-dienoic acid (WIT003), induced mitogenesis in endothelial cells and corneal neovascularization in vivo [102]. These studies provide experimental evidence that inhibiting 20-HETE may offer a strategy to reduce pathological angiogenesis not only in tumors but also in angiogenic diseases such as diabetic retinopathy, macular degeneration, and chronic inflammatory diseases such as psoriasis [102]. However, in these studies, it was not determined whether the cornea or endothelial cells produced 20-HETE; therefore, further studies are needed [108].

In the systemic circulation, 20-HETE produced by vascular smooth muscle cells acts as a vasoconstrictor [6]. However, in pulmonary arteries, 20-HETE contributes to the VEGFinduced relaxation of the lungs [109]. VEGF is a nitric oxide (NO)-dependent dilator of systemic arteries and plays a key role in maintaining the integrity of the pulmonary vasculature [109]. 


\section{20-HETE effects in cancer}

The role of LOX-derived and CYP-derived HETEs in cancer biology has been extensively reviewed by Moreno [60]. In 2008, U251 glioblastoma cells were genetically altered (transfected with rat CYP4A1 cDNA) to increase the formation of 20-HETE [110]. This stimulated tumor cell proliferation in culture. When these U251 glioblastoma cells were implanted into the brain of rats, a tenfold increase in tumor volume versus animals receiving mock-transfected U251 cells was observed [110].

In contrast to the strategy to increase 20-HETE, Guo et al. [108] demonstrated that HET0016 significantly inhibited human U251 glioblastoma cell proliferation in a dosedependent manner. HET0016 inhibited the phosphorylation of the epidermal growth factor receptor (EGFR) and the subsequent phosphorylation of p42/p44 MAPK [108]. While U251 cells expressed CYP4A11 mRNA and protein, HPLC and mass spectrometry analysis of U251 cells revealed that they did not appear to synthesize 20-HETE [108]. Thus, HET0016 has other effects independent of suppressing 20-HETE. Subsequently, the same group demonstrated that 9L gliosarcoma proliferation and tumor growth in rats were suppressed by HET0016 [111]. Systemic administration of HET0016 inhibited the tumor growth of 9L gliosarcomas by $80 \%$ and tumor angiogenesis by roughly $50 \%$. In a separate study, HET0016 and a 20-HETE antagonist (WIT002) both inhibited the proliferation of a renal adenocarcinoma. This cell type expressed CYP4F isoforms and produced 20-HETE [112]. Recent studies show that CYP $\omega$-hydroxylase (via CYP4A11 transfection of tumor cells) promoted angiogenesis and metastasis associated with an increase of VEGF and MMP9 in non-small cell lung cancer cells [113].

Little is known about 20-HETE in cancer patients. In one study, 12-HETE and 20-HETE concentrations were shown to be elevated in the urine of patients with benign prostatic hypertrophy and prostate cancer as compared with normal subjects [114]. Further analysis did not establish a correlation between the concentrations of HETEs and PSA level, gland size, or tumor grade [114].

\section{EET signaling in angiogenesis}

EETs are mainly secreted by endothelial cells and play critical roles in cellular proliferation, migration, and inflammation $[8,50]$. The EET-producing enzymes of the CYP2C and CYP2J subfamilies have been found in endothelial cells in vitro and in vivo [7, 17]. EETs may act in an autocrine fashion on the endothelium inducing vasodilatory and antiinflammatory effects in blood vessels [9]. As a result of these effects, EETs lower blood pressure and protect the myocardium and brain from ischemia $[28,70]$.

The initial finding that linked EETs to angiogenesis was shown by the increased proliferation of cerebral capillary endothelial cells in vitro by culture media from astrocytes [18]. In contrast, an inhibitor of cytochrome P450, 17-octadecynoic acid (17-ODYA), suppressed the formation of capillary tubes in a co-culture of astrocytes and endothelial cells. Both EETs secreted by astrocytes and synthetic EETs stimulated endothelial cell proliferation, tube formation, and angiogenesis in a Matrigel plug in vivo [18, 115, 116].

Angiogenesis is critically dependent on endothelial cell migration [117]. The development of synthetic EETs has provided insight into the angiogenic functions and pathways of the various EETs. For instance, EETs have been shown to promote endothelial cell migration via eNOS, MEK/MAPK, and PI3-K [19]. Another optimal assay to evaluate angiogenesis is the chick chorioallantoic membrane assay, which uses the chorioallantoic membrane (CAM) of a chicken embryo [118]. Michaelis et al. [119] employed this assay to demonstrate that 11,12-EET stimulates vessel formation. Importantly, this CAM-mediated angiogenesis was 
suppressed by either an EGF receptor-neutralizing antibody or an inhibitor of the EGF receptor. Thus, 11,12-EET may stimulate angiogenesis through the activation of the EGF receptor [119].

Several pathways have been implicated in 11,12-EET-and 14,15-EET-mediated angiogenesis. Sphingosine kinase-1 (SK1) is one important mediator of 11,12-EET-induced angiogenic effects [120]. The expression of a dominant-negative SK1 or knockdown of SK1 by siRNA inhibited 11,12-EET-induced endothelial cell proliferation, migration, tube formation, and Matrigel plug vessel formation [120]. The availability of these synthetic EETs has made it possible to evaluate another regioisomer, 14,15-EET. 14,15-EET was shown to induce angiogenesis through several pathways, including Src, PI3K/Akt signaling in parallel with mTOR-S6K1 activation, and Src-dependent STAT-3-mediated VEGF expression [121, 122].

Other groups have studied CYP 450-derived metabolites utilizing the strategy of overexpressing CYP epoxygenases. This system inhibited endothelial cell apoptosis through the activation of a PI3K/Akt pathway [123]. This overexpression of CYP epoxygenases, including CYP2J2, increased muscle capillary density in a rat ischemic hind limb model [19]. Thus, CYP 450-derived metabolites may stimulate the development of collateral circulation in ischemic tissue [19]. While most investigators have focused on 11,12-EET and 14,15-EET, Pozzi et al. [17] identified 5,6-EET and 8,9-EET as pro-angiogenic lipids. These regioisomers increased blood vessel density and formed functionally intact vessels in a subcutaneous sponge model in mice. This neovascularization was enhanced by the coadministration of a soluble epoxide hydrolase inhibitor which elevates the levels of EETs [17]. This study corroborates the critical role that EETs plays in angiogenesis.

It is known that hypoxia stimulates angiogenesis via transcriptional VEGF induction, a response that is mediated by the hypoxia-inducible factor-1a (HIF-1a) [124]. It was shown by the Fleming laboratory that a state of hypoxia also stimulates CYP2C8 and CYP2C9 expression $[7,125,126]$. Consistently, the putative EET receptor antagonist, 14,15-EEZE, inhibited hypoxia-induced endothelial tube formation. This study showed that the angiogenic effect of EETs is partially dependent on HIF-1a-mediated VEGF induction [127]. This may have implications in cancer beyond angiogenesis since HIF-1a can provide growth and survival advantages to tumor cells, especially under metabolic stress [90].

The effects of EETs and VEGF regulation are closely intertwined. EETs can enhance the effects of VEGF-induced angiogenesis [128]. In turn, VEGF can increase the CYP2C promoter activity in endothelial cells and induce the expression of CYP2C8, resulting in increased intracellular EET levels [128]. The putative EET receptor antagonist, 14,15EEZE, inhibits VEGF-induced endothelial cell tube formation. However, 14,15-EEZE does not affect the VEGF-induced phosphorylation of its receptor or FGF-2-stimulated tube formation. In a parallel study, CYP2C44 epoxygenase appears to be an important component in the VEGF signaling pathway [129]. For example, in cultured lung endothelial cells that express VEGF-inducible Cyp2c44 epoxygenase, resulting in increased levels of 11,12-EET and 14,15-EET, angiogenesis was stimulated in vitro. Taken together, these studies suggest that the pro-angiogenic activity of EETs is mediated, at least in part, by VEGF $[128,129]$.

\section{EETs and inflammation}

Pioneering studies from the Hammock laboratory demonstrate that soluble epoxide hydrolase is a therapeutic target for inflammation $[5,130]$. In contrast to COX/LOX inhibitors, which directly inhibit the production of pro-inflammatory mediators, soluble epoxide hydrolase inhibitors promote the formation of pro-resolution mediators such as 
lipoxin $\mathrm{A}_{4}$ [130]. Soluble epoxide hydrolase inhibitors such as 12-(3-adamantan-1-ylureido)-dodecanoic acid butyl ester (AUDA-BE) stabilize anti-inflammatory EETs, which indirectly reduces the expression of COX-2, 5-LOX, iNOS, and VCAM-1 [131, 132]. AUDA-BE decreases the protein expression of COX-2 without altering COX-1 expression and decreases inflammatory eicosanoid levels in lipopolysaccharide-challenged mice [131]. When AUDA-BE was used in combination with low doses of indometh-acin, celecoxib, or rofecoxib, $\mathrm{PGE}_{2}$ concentrations were reduced. Thus, soluble epoxide hydrolase inhibitors synergize with NSAIDs and COX-2 inhibitors in suppressing inflammation [131].

The administration of a soluble epoxide hydrolase inhibitor in a mouse colitis model resulted in decreased ulcer incidences [132]. Based on the anti-inflammatory effects of soluble epoxide hydrolase inhibitors, one may expect these agents to have anticancer effects based solely on their anti-inflammatory activity. Also, the inhibition of EPHX2 (epoxide hydrolase 2) in vitro induced cancer cell apoptosis, decreased androgen receptor signaling, and potentiated the anti-proliferative of the anti-androgen flutamide for prostate cancer treatment [133]. However, soluble epoxide hydrolase inhibitors exhibit pro-angiogenic activity [17]. Since tumor growth is angiogenesis-dependent [79], soluble epoxide hydrolase inhibitors may have a biphasic effect on tumor growth.

\section{Cytochrome P450 epoxygenases and cancer}

Recent studies have associated CYP epoxygenases with cancer; however, the role of EETs in cancer remains poorly characterized [11]. Although two decades ago 14,15-EET was shown to stimulate mesangial and renal epithelial cell proliferation [134, 135], only in the last 5 years has evidence supporting cytochrome $\mathrm{P} 450$ epoxygenases as a potential tumorpromoting enzyme begun to emerge [136]. The role of CYP2J2 epoxygenase in cancer was first shown by Jiang et al. [136]. In this study, CYP2J2 was upregulated in 77\% of human carcinoma tissues and eight different human carcinoma cell lines [136]. Furthermore, the transfection of tumor cells with CPY2J2 epoxygenase enhanced tumor cell proliferation, prevented tumor cell apoptosis, and increased tumor growth [136]. CYP2J2 is also highly expressed in malignant hematological cell lines and promoted xenograft tumor growth in leukemia models [137].

Subsequent studies from the Wang laboratory in which CYP epoxygenase levels were manipulated, by either overexpression of CYP2J2 or antisense in the xenotrans-planted tumor cell, suggest that EETs may play a role in cancer metastasis [12]. In these studies, the overexpression of CYP2J2 or the addition of synthetic EETs in vitro induced cancer cell migration and invasion. Recombinant adeno-associated viral vector (rAAV)-CYP2J2infected human breast carcinoma cells resulted in $60 \%$ more lung metastases. Additional metastases in the liver and bladder were found only in the CYP2J2-transfected group. Lung metastasis was prevented by infection with an antisense rAAV-CYP2J2 vector [12]. Treatment of carcinoma cells in vitro with exogenous EETs or the overexpression of CYP2J2 resulted in an increase in metalloproteinases (MMP-9) and CD44 expression and decreased CD82 and nm-23 expression [12]. Metalloproteinases are activated by EETs in cancer cells and lead to the EET-induced trans-activation of EGFR, which subsequently releases the pro-angiogenic factor HB-EGF in cancer cell lines [138].

EETs also appear to be important for cancer cell survival. Further studies from the Wang laboratory show that specific inhibitors of CYP2J2 related to the drug terfenadine decrease human tumor cell proliferation, adhesion, migration, and invasion. These inhibitors also activate caspase-3, enhance human tumor cell apoptosis, and inhibit murine xenograft tumor growth [139]. Reduced levels of 14,15-DHET accompanied the antitumor effects of CYP2J2 inhibitors. Since there were no overt signs of toxicity, CYP2J2 inhibitors may have 
therapeutic efficacy in the treatment of cancer. Often it is difficult to distinguish a direct effect on tumor cells versus an effect on stromal processes. It is likely that both mechanisms synergize to account for the potential pro-tumorigenic activity of EETs.

There are few pharmacological studies using drugs which can nonspecifically affect EETs and PPARa. PPARa is a ligand-activated transcription factor and a target of the fibrate family of anti-hyperlipidemic drugs [14, 140]. In one study conducted by Pozzi et al. [14], mice treated with PPARa ligands exhibited a reduction of tumor growth, vascularization, plasma EETs, hepatic EET biosynthesis, and CYP2C epoxygenase expression. The tumor cell-suppressive effect of the PPARa ligand WY-14643 in vitro was abrogated when EETs were added to the culture [14]. Further studies by Pozzi et al. [16] showed that the antitumorigenic properties of PPARa are epoxygenase-mediated. The activation of human PPARa downregulates the expression of endothelial cell CYP2C9 epoxygenase. In a mouse xenograft model of tumorigenesis, disruption of host Cyp2c44 epoxygenase suppressed tumor growth and vascularization [16]. This Cyp2c44 epoxygenase is a target of the antitumor effects of PPARa ligand activation [16].

PPARa ligands are also potent inducers of sEH in rodents [141], further accentuating the suppression of net EET production. PPARa itself may underlie the reduction of EETs by PPARa ligand activation. PPARa-responsive elements have not been found upstream of the human EPHX2 [142]. Thus, the correlation of tumor suppression and the decrease of EETs in response to PPARa treatment as well as the known angiogenic activity of EETs strongly suggest a causal-mechanistic connection, namely, that EETs act as a key mediator of the anti-tumor and anti-angiogenic effects of PPARa. Wray and Bishop-Bailey [143] have detailed the link between epoxygenases and PPARs in vascular biology. Interestingly, EETs as well as the activation of PPARa and PPARY result in the inhibition of endothelial cell proliferation, migration, and inflammation. Cytochome $\mathrm{P} 450$ eicosanoids can bind to and activate PPARa [144]. Linking CYP2J2 and epoxygenases was demonstrated by Wray et al. by showing that the epoxygenase CYP2J2 activates PPARa in vitro and in vivo and that the CYP2J2 products 8,9- and 11,12-EET activate PPARa [143, 145].

The family of PPAR receptors has attracted interest as a potential target for anticancer therapy due to their anti-proliferative, pro-apoptotic, and pharmacological accessibility. We found that the PPARa agonist, fenofibrate, dramatically suppressed tumor growth through the inhibition of angiogenesis and the tumor-supporting inflammatory process [140]. Therefore, these drugs, which were originally developed as anti-inflammatory agents, may be used for cancer treatment. Based on our studies [14, 140], a multi-institutional phase II clinical trial testing the efficacy of PPARa-activating drug (fibrates) in combination with oral anti-angiogenesis drugs against recurrent/progressive pediatric cancers is currently being evaluated [146].

EETs have been detected in both normal and brain tumor tissue [147]. In a separate study, two mechanistically different synthetic inhibitors of cytochrome P450, 17-ODYA and miconazole, significantly reduced tumor size and capillary formation in intracranial glial tumors and prolonged the survival of treated rats [147]. Interestingly, these inhibitors had no effect on EETs in the tumor tissue, suggesting that the tumor endothelium may be the target of these CYP inhibitors [147]. It has recently been reported that EET antagonists inhibit prostate carcinoma cell motility [148]. This may represent a novel mechanism of EET antagonists acting directly on the tumor cell [148].

Several CYP epoxygenases have been detected in tumor cells in vitro and in vivo, supporting the potential role of EETs in cancer (Fig. 3). For instance, CYP2C8, CYP2C9, and CYP2J2 were recently shown to be expressed in three prostate carcinoma cell lines 
(PC3, DU-145, and LNCaP) [148]. In these studies, no consistent correlation between mRNA expression, protein expression, or EET concentrations was found. Another epoxygenase, CYP2C11, was shown by Zagorac et al. [147] to be upregulated in cerebral brain tumors of rats. In addition to tumor cells, Pozzi et al. [17] showed that CYP epoxygenases are also expressed in the tumor stroma. For example, Cyp2c44 epoxygenase is expressed in the tumor vessels of a xenograft model of human non-small cell lung cancer in mice. Furthermore, CYP2C9 epoxygenase was recently found to be selectively expressed in the vasculature of human renal tumors [16]. These findings open the possibility that EETs may act as a trophic factor for both tumor stroma and parenchyma.

Recombinant human CYP3A4 can generate EETs from arachidonic acid [61]. Recent studies by Mitra et al. [149] show that CYP3A4 epoxygenase promotes the growth of estrogen receptor-positive breast cancer cells, in part through the biosynthesis of 14,15-EET. CYP3A and CYP2C8, but not CYP2J2, promoted breast cancer growth in these studies. Similarly, the overexpression of CYP3A4 increased cancer cell growth of hepatocarcinoma, which was inhibited by the addition of the putative EET receptor antagonist, 14,15-EEZE [61]. Both of these studies suggest that CYP3A4 can increase cancer cell growth [149, 150]. Other studies show that esophageal cancer cell proliferation is in part mediated by CYP2C9 in an 11,12-EET-dependent fashion [151].

In earlier clinical studies, 14,15-EET levels were detected in the urine samples of patients with benign prostatic hypertrophy and prostate cancer in comparison to normal volunteers. Interestingly, after the removal of the prostate gland in prostate cancer patients, the urinary concentration of 14,15-EET did not decrease. These data suggest that the origin of the 14,15-EET was not the prostate gland but another source [114].

Whether the levels of CYP epoxygenases are dependent on isoenzyme or tumor type remains up for debate. CYP2C expression is increased in metastatic liver tissues compared with normal liver tissue [152]. Enayetallah et al. [153] analyzed three cytochrome P450 epoxygenases (CYP2C8, CYP2C9, and CYP2J2) and sEH in human malignant neoplasms. CYP2C9 was the most abundantly expressed epoxygenase. Both CYP2C8 and CYP2C9 were expressed in human malignant neoplasms such lung adenocarcinoma, breast ductal carcinoma, colon adenocarcinoma, basal cell carcinoma, bladder transitional cell carcinoma, ovarian adenocarcinoma, endometrial carcinoma, and adenocarcinoma of the prostate [153]. In contrast, CYP2J2 staining was not detected in pancreatic or prostate adenocarcinoma. Furthermore, CYP2J2 expression was detected in $<50 \%$ of lung squamous cell carcinoma (SCC) samples and in $<15 \%$ of lung adenocarcinoma samples [153]. These results showing that CYP2J2 can be underexpressed were confirmed by Leclerc et al. [154] showing that CYP2J2 was underexpressed in all of their SCC samples. Three other CYP epoxygenases (CYP2C8, CYP2C9, and CYP2C19) were also underexpressed in SCC [154]. It has been suggested that this decrease in arachidonic acid epoxidation in certain tumors may allow arachidonic acid to be metabolized to the other eicosanoids [154].

CYP2J2 was almost undetectable in breast cancer and did not correlate with tumor grade or estrogen status [155]. In these studies by Murray et al., of the 21 cytochrome P450s whose expression in breast cancer was profiled, the highest expression was that of CYP2S1,

CYP4X1, and CYP3A4. In contrast, previous studies have shown a moderate expression of CYP2J2 in breast cancer [153]. The expression of CYP2C8 in esophageal adenocarcinoma was downregulated fivefold compared with para-cancerous tissue. In other studies in renal carcinoma, cytochrome P450 arachidonic acid epoxygenase activity was markedly reduced in the tumor tissues and decreased in tumor cells [156]. Consequently, the inconsistent overexpression and underexpression of CYP epoxygenases in tumors makes it difficult to 
understand the biological significance of these enzymes in cancer. This variability must be examined in the wider context of the complex metabolic pathways of lipid autacoids.

The expression of sEH, the main metabolizing enzyme of EETs, has been investigated in cancer. Loss of sEH has been reported in hepatocellular carcinoma and hepatoma cells [157, 158]. Enayetallah et al. [153] further confirmed that $\mathrm{sEH}$ can be downregulated in renal and hepatic tumors, in principle increasing the levels of EETs in the tumor tissue. These studies support a potential role for EETs in cancer due to its metabolizing enzyme being downregulated. The authors here suggested that the loss of sEH expression may result in an increase of cancer-promoting EETs versus "anti-carcinogenic" isoprenols, with a resulting effect of carcinogenesis [153]. However, the expression of sEH can also be upregulated in other cancers. sEH expression was increased in seminoma, cholangiocarci-noma, and advance ovarian cancer when compared with normal tissues or early-stage cancer [153]. sEH is a multifunctional protein encoded by the EPHX2 (epoxide hydrolase 2) gene [142]. EPHX2 was expressed at the same level in both clinical prostate cancer samples and normal prostate samples [133]. EPHX2 also correlated with androgen receptor mRNA in clinical prostate cancer samples. EPHX2 has been identified as a candidate metastasis suppressor gene in breast cancer [159]. In preliminary studies on human tissues, sEH expression was increased in ulcerative colitis, ulcerative-induced dysplasia, and ulcerative colitis-induced carcinoma [132]. As in the case of CYP epoxygenases, there is no consistent finding in the expression of sEH in tumors. According to the rationale that the elevation of EETs in tissues promotes tumor growth, sEH would be expected to be downregulated in tumors-which is observed only in certain tumors. More studies will be needed to reveal whether a potential increase of EETs or tumor sEH expression is associated with a particular tumor type or cancer stage.

There is another aspect to consider about CYP expression in cancer. CYP 2C8 metabolizes drugs such as paclitaxel (Taxol), tamoxifen, and other chemotherapy agents [160]; therefore, genetic polymorphisms in the CYP2C8/9 gene may affect cancer survival. Polymorphisms in human CYP2C8 have been identified, and it decreases the metabolism of paclitaxel and arachidonic acid [161]. Recent studies have shown that genetic polymorphisms in CYP2C8 and CYP2C9 influence disease-free survival of breast cancer patients [162]. The CYP2C $8 * 3$ allele was associated with early breast cancer-related events in women treated with tamoxifen. However, other studies showed that CYP2C8 and CYP2J2 were not associated with overall survival in breast cancer [155]. These studies did correlate CYP3A4 and CYP2S1 with breast cancer survival [155]. Furthermore, a genetic polymorphism of CYP2C19 is associated with susceptibility to biliary tract cancer [163]. There are several polymorphisms in the gene for sEH (EPHX2) that affect sEH enzymatic activity and coronary artery disease $[164,165]$. Further studies are required to determine whether these populations are at altered risk of cancer.

\section{Outlook}

Many classes of drugs which were originally found to target inflammation and cardiovascular diseases have been discovered to play an important role in cancer biology. This appears to also be the case with cytochrome P450-derived metabolites of arachidonic acid, the epoxyeicosatrienoic acids (EETs) and hydroxyeicosatetraenoic acids (HETEs), in particular 20-HETE. These eicosanoids may be involved in cell-autonomous tumor survival and growth as well as in promoting stromal processes that support tumor progression. As much as classical mediators of inflammation, such as prostaglandins, have received new attention as targets in cancer treatment, the EETs should be evaluated as potential targets in cancer therapy. The known synthesis (CYP expoxygenases) and degradation pathway (soluble epoxide hydrolase) of EETs offer pharmacologically accessible lever points to 
control the cellular and circulating levels of EETs. However, the role of EETs in cancer is still poorly characterized in part because of their biochemical complexity. The isolation of the EET receptors will be critical to understand the molecular mechanisms of the potent protumorigenic activity of EETs in cancer. This could advance the field similar to the discovery of multiple prostaglandin $\mathrm{E}_{2}\left(\mathrm{PGE}_{2}\right)$ receptors [166]. The increasing availability of research tools, such as novel synthetic agonists and antagonists, as well as enzyme inhibitors, offer a reasonable platform for dissecting the role of EETs in cancer. Clearly, much work lies ahead if we are to unravel the molecular, cellular, and biological mechanisms of EETs in cancer. This review not only describes the many important findings to date from several laboratories but also reveals large gaps in our knowledge. Thus, rather than providing a unifying answer, it may hopefully inspire further research.

\section{Acknowledgments}

We thank Sui Huang and Arja Kaipainen for suggestions in preparing the manuscript; Kristin Johnson for preparation of figures. This work was supported by National Cancer Institute grant RO1CA148633-O1A1 (DP); 2PO1DK38226 (AP); Division of Intramural Research of the NIH, National Institute of Environmental Health Sciences - Z01 ES025034 and Z01 ES050167 (DCZ).

\section{References}

1. Wang D, Dubois RN. Eicosanoids and cancer. Nature Reviews Cancer. 2010; 10:181-193.

2. Pidgeon GP, Lysaght J, Krishnamoorthy S, Reynolds JV, O'Byrne K, Nie D, et al. Lipoxygenase metabolism: Roles in tumor progression and survival. Cancer Metastasis Reviews. 2007; 26:503524. [PubMed: 17943411]

3. Zeldin DC. Epoxygenase pathways of arachidonic acid metabolism. Journal of Biological Chemistry. 2001; 276:36059-36062. [PubMed: 11451964]

4. Serhan, CN.; Haeggstrom, JZ., editors. Lipid mediatorsin acute inflammation and resolution: Eicosanoids, PAF, resolvins, and protectins. Cambridge: Cambridge University Press; 2009.

5. Imig JD, Hammock BD. Soluble epoxide hydrolase as a therapeutic target for cardiovascular diseases. Nature Reviews Drug Discovery. 2009; 8:794-805.

6. Roman RJ. P-450 metabolites of arachidonic acid in the control of cardiovascular function. Physiological Reviews. 2002; 82:131-185. [PubMed: 11773611]

7. Fleming I. Epoxyeicosatrienoic acids, cell signaling and angiogenesis. Prostaglandins \& Other Lipid Mediators. 2007; 82:60-67. [PubMed: 17164133]

8. Spector AA, Norris AW. Action of epoxyeicosatrienoic acids on cellular function. American Journal of Physiology Cell Physiology. 2007; 292:C996-1012. [PubMed: 16987999]

9. Fleming I. Vascular cytochrome p450 enzymes: Physiology and pathophysiology. Trends in Cardiovascular Medicine. 2008; 18:20-25. [PubMed: 18206805]

10. Campbell WB, Falck JR. Arachidonic acid metabolites as endothelium-derived hyperpolarizing factors. Hypertension. 2007; 49:590-596. [PubMed: 17200437]

11. Panigrahy D, Kaipainen A, Greene ER, Huang S. Cytochrome P450-derived eicosanoids: The neglected pathway in cancer. Cancer Metastasis Reviews. 2010; 29:723-735. [PubMed: 20941528]

12. Jiang JG, Ning YG, Chen C, Ma D, Liu ZJ, Yang S, et al. Cytochrome p450 epoxygenase promotes human cancer metastasis. Cancer Research. 2007; 67:6665-6674. [PubMed: 17638876]

13. Xu X, Zhang XA, Wang DW. The roles of CYP450 epoxygenases and metabolites, epoxyeicosatrienoic acids, in cardiovascular and malignant diseases. Advance Drug Delivery Review. 2011; 63:597-609.

14. Pozzi A, Ibanez MR, Gatica AE, Yang S, Wei S, Mei S, et al. Peroxisomal proliferator-activated receptor-alpha-dependent inhibition of endothelial cell proliferation and tumorigenesis. Journal of Biological Chemistry. 2007; 282:17685-17695. [PubMed: 17405874]

15. Pozzi A, Capdevila JH. PPARalpha ligands as antitumorigenic and antiangiogenic agents. PPAR Research. 2008; 2008:906542. [PubMed: 18725983] 
16. Pozzi A, Popescu V, Yang S, Mei S, Shi M, Puolitaival SM, et al. The anti-tumorigenic properties of peroxisomal proliferator-activated receptor alpha are arachidonic acid epoxygenase-mediated. Journal of Biological Chemistry. 2010; 285:12840-12850. [PubMed: 20178979]

17. Pozzi A, Macias-Perez I, Abair T, Wei S, Su Y, Zent R, et al. Characterization of 5,6- and 8,9epoxyeicosatrienoic acids (5,6- and 8,9-EET) as potent in vivo angiogenic lipids. Journal of Biological Chemistry. 2005; 280:27138-27146. [PubMed: 15917237]

18. Munzenmaier DH, Harder DR. Cerebral microvascular endothelial cell tube formation: Role of astrocytic epoxyeicosatrienoic acid release. American Journal of Physiology Heart and Circulatory Physiology. 2000; 278:H1163-1167. [PubMed: 10749710]

19. Wang Y, Wei X, Xiao X, Hui R, Card JW, Carey MA, et al. Arachidonic acid epoxygenase metabolites stimulate endothelial cell growth and angiogenesis via mitogen-activated protein kinase and phosphatidylinositol 3-kinase/Akt signaling pathways. Journal of Pharmacology and Experimental Therapeutics. 2005; 314:522-532. [PubMed: 15840765]

20. Node K, Huo Y, Ruan X, Yang B, Spiecker M, Ley K, et al. Anti-inflammatory properties of cytochrome P450 epoxygenase-derived eicosanoids. Science. 1999; 285:1276-1279. [PubMed: 10455056]

21. Hardwick JP, Song BJ, Huberman E, Gonzalez FJ. Isolation, complementary DNA sequence, and regulation of rat hepatic lauric acid omega-hydroxylase (cytochrome P-450LA omega). Identification of a new cytochrome P-450 gene family. Journal of Biological Chemistry. 1987; 262:801-810. [PubMed: 3027069]

22. Powell PK, Wolf I, Jin R, Lasker JM. Metabolism of arachidonic acid to 20-hydroxy-5,8,11,14eicosatetraenoic acid by P450 enzymes in human liver: involvement of CYP4F2 and CYP4A11. Journal of Pharmacology and Experimental Therapeutics. 1998; 285:1327-1336. [PubMed: 9618440]

23. Miyata N, Roman RJ. Role of 20-hydroxyeicosatetraenoic acid (20-HETE) in vascular system. Journal of Smooth Muscle Research. 2005; 41:175-193. [PubMed: 16258232]

24. Fisslthaler B, Popp R, Kiss L, Potente M, Harder DR, Fleming I, et al. Cytochrome P450 2C is an EDHF synthase in coronary arteries. Nature. 1999; 401:493-497. [PubMed: 10519554]

25. Kaspera R, Totah RA. Epoxyeicosatrienoic acids: Formation, metabolism and potential role in tissue physiology and pathophysiology. Expert Opinion on Drug Metabolism \& Toxicology. 2009; 5:757-771. [PubMed: 19505190]

26. Zeldin DC, Kobayashi J, Falck JR, Winder BS, Hammock BD, Snapper JR, et al. Regio- and enantiofacial selectivity of epoxyeicosatrienoic acid hydration by cytosolic epoxide hydrolase. Journal of Biological Chemistry. 1993; 268:6402-6407. [PubMed: 8454612]

27. Yu Z, Xu F, Huse LM, Morisseau C, Draper AJ, Newman JW, et al. Soluble epoxide hydrolase regulates hydrolysis of vasoactive epoxyeicosatrienoic acids. Circulation Research. 2000; 87:992998. [PubMed: 11090543]

28. Simpkins AN, Rudic RD, Schreihofer DA, Roy S, Manhiani M, Tsai HJ, et al. Soluble epoxide inhibition is protective against cerebral ischemia via vascular and neural protection. American Journal of Pathology. 2009; 174:2086-2095. [PubMed: 19435785]

29. Chacos N, Capdevila J, Falck JR, Manna S, Martin-Wixtrom C, Gill SS, et al. The reaction of arachidonic acid epoxides (epoxyeicosatrienoic acids) with a cytosolic epoxide hydrolase. Archives of Biochemistry and Biophysics. 1983; 223:639-648. [PubMed: 6859878]

30. Capdevila JH, Harris RC, Falck JR. Microsomal cytochrome P450 and eicosanoid metabolism. Cellular and Molecular Life Sciences. 2002; 59:780-789. [PubMed: 12088278]

31. Capdevila J, Chacos N, Werringloer J, Prough RA, Estabrook RW. Liver microsomal cytochrome P-450 and the oxidative metabolism of arachidonic acid. Proceedings of the National Academy of Sciences of the United States of America. 1981; 78:5362-5366. [PubMed: 6795631]

32. Capdevila J, Marnett LJ, Chacos N, Prough RA, Estabrook RW. Cytochrome P-450-dependent oxygen-ation of arachidonic acid to hydroxyicosatetraenoic acids. Proceedings of the National Academy of Sciences of the United States of America. 1982; 79:767-770. [PubMed: 6801662]

33. Morrison AR, Pascoe N. Metabolism of arach-idonate through NADPH-dependent oxygenase of renal cortex. Proceedings of the National Academy of Sciences of the United States of America. 1981; 78:7375-7378. [PubMed: 6801649] 
34. Oliw EH, Lawson JA, Brash AR, Oates JA. Arachidonic acid metabolism in rabbit renal cortex. Formation of two novel dihydroxyeicosatrienoic acids. Journal of Biological Chemistry. 1981; 256:9924-9931. [PubMed: 6792198]

35. Campbell WB, Gebremedhin D, Pratt PF, Harder DR. Identification of epoxyeicosatrienoic acids as endothelium-derived hyperpolarizing factors. Circulation Research. 1996; 78:415-423. [PubMed: 8593700]

36. Zeldin DC, Foley J, Ma J, Boyle JE, Pascual JM, Moomaw CR, et al. CYP2J subfamily P450s in the lung: Expression, localization, and potential functional significance. Molecular Pharmacology. 1996; 50:1111-1117. [PubMed: 8913342]

37. Morisseau C, Goodrow MH, Dowdy D, Zheng J, Greene JF, Sanborn JR, et al. Potent urea and carbamate inhibitors of soluble epoxide hydrolases. Proceedings of the National Academy of Sciences of the United States of America. 1999; 96:8849-8854. [PubMed: 10430859]

38. Nelson DR, Zeldin DC, Hoffman SM, Maltais LJ, Wain HM, Nebert DW. Comparison of cytochrome P450 (CYP) genes from the mouse and human genomes, including nomenclature recommendations for genes, pseudogenes and alternative-splice variants. Pharmacogenetics. 2004; 14:1-18. [PubMed: 15128046]

39. Nebert DW, Russell DW. Clinical importance of the cytochromes P450. Lancet. 2002; 360:11551162. [PubMed: 12387968]

40. Wang H, Zhao Y, Bradbury JA, Graves JP, Foley J, Blaisdell JA, et al. Cloning, expression, and characterization of three new mouse cytochrome p450 enzymes and partial characterization of their fatty acid oxidation activities. Molecular Pharmacology. 2004; 65:1148-1158. [PubMed: 15102943]

41. Finta C, Zaphiropoulos PG. The human CYP2C locus: A prototype for intergenic and exon repetition splicing events. Genomics. 2000; 63:433-438. [PubMed: 10704292]

42. Waxman DJ, Chen L, Hecht JE, Jounaidi Y. Cytochrome P450-based cancer gene therapy: Recent advances and future prospects. Drug Metabolism Reviews. 1999; 31:503-522. [PubMed: 10335450]

43. Nebert DW, Dalton TP. The role of cytochrome P450 enzymes in endogenous signalling pathways and environmental carcinogenesis. Nature Reviews Cancer. 2006; 6:947-960.

44. Swanson HI, Njar VC, Yu Z, Castro DJ, Gonzalez FJ, Williams DE, et al. Targeting drugmetabolizing enzymes for effective chemoprevention and chemotherapy. Drug Metabolism and Disposition. 2010; 38:539-544. [PubMed: 20233842]

45. Lu H, Chen CS, Waxman DJ. Potentiation of methoxymorpholinyl doxorubicin antitumor activity by P450 3A4 gene transfer. Cancer Gene Therapy. 2009; 16:393-404. [PubMed: 19011599]

46. Jordan VC, Brodie AM. Development and evolution of therapies targeted to the estrogen receptor for the treatment and prevention of breast cancer. Steroids. 2007; 72:7-25. [PubMed: 17169390]

47. Bruno RD, Njar VC. Targeting cytochrome P450 enzymes: A new approach in anti-cancer drug development. Bioorganic \& Medicinal Chemistry. 2007; 15:5047-5060. [PubMed: 17544277]

48. Moreira VM, Salvador JA, Vasaitis TS, Njar VC. CYP17 inhibitors for prostate cancer treatmentAn update. Current Medicinal Chemistry. 2008; 15:868-899. [PubMed: 18473796]

49. Rosolowsky M, Campbell WB. Synthesis of hydroxyeicosatetraenoic (HETEs) and epoxyeicosatrienoic acids (EETs) by cultured bovine coronary artery endothelial cells. Biochimica et Biophysica Acta. 1996; 1299:267-277. [PubMed: 8555273]

50. Fleming I. DiscrEET regulators of homeostasis: Epoxyeicosatrienoic acids, cytochrome P450 epoxygenases and vascular inflammation. Trends in Pharmacological Sciences. 2007; 28:448-452. [PubMed: 17764757]

51. Alkayed NJ, Narayanan J, Gebremedhin D, Medhora M, Roman RJ, Harder DR. Molecular characterization of an arachidonic acid epoxygenase in rat brain astrocytes. Stroke. 1996; 27:971979. [PubMed: 8623121]

52. Amruthesh SC, Boerschel MF, McKinney JS, Willoughby KA, Ellis EF. Metabolism of arachidonic acid to epoxyeicosatrienoic acids, hydroxyeicosatetraenoic acids, and prostaglandins in cultured rat hippo-campal astrocytes. Journal of Neurochemistry. 1993; 61:150-159. [PubMed: 8515261] 
53. Wu S, Moomaw CR, Tomer KB, Falck JR, Zeldin DC. Molecular cloning and expression of CYP2J2, a human cytochrome $\mathrm{P} 450$ arachidonic acid epoxygenase highly expressed in heart. Journal of Biological Chemistry. 1996; 271:3460-3468. [PubMed: 8631948]

54. Wu S, Chen W, Murphy E, Gabel S, Tomer KB, Foley J, et al. Molecular cloning, expression, and functional significance of a cytochrome $\mathrm{P} 450$ highly expressed in rat heart myocytes. Journal of Biological Chemistry. 1997; 272:12551-12559. [PubMed: 9139707]

55. Nakayama K, Nitto T, Inoue T, Node K. Expression of the cytochrome P450 epoxygenase CYP2J2 in human monocytic leukocytes. Life Sciences. 2008; 83:339-345. [PubMed: 18675280]

56. Nieves D, Moreno JJ. Hydroxyeicosatetraenoic acids released through the cytochrome P-450 pathway regulate 3T6 fibroblast growth. Journal of Lipid Research. 2006; 47:2681-2689. [PubMed: 16980726]

57. Muthalif MM, Benter IF, Karzoun N, Fatima S, Harper J, Uddin MR, et al. 20Hydroxyeicosatetraenoic acid mediates calcium/calmodulin-dependent protein kinase II-induced mitogen-activated protein kinase activation in vascular smooth muscle cells. Proceedings of the National Academy of Sciences of the United States of America. 1998; 95:12701-12706. [PubMed: 9770549]

58. Schwartzman ML, Falck JR, Yadagiri P, Escalante B. Metabolism of 20-hydroxyeicosatetraenoic acid by cyclooxygenase. Formation and identification of novel endothelium-dependent vasoconstrictor metabolites. Journal of Biological Chemistry. 1989; 264:11658-11662. [PubMed: 2501294]

59. Kaduce TL, Fang X, Harmon SD, Oltman CL, Dellsperger KC, Teesch LM, et al. 20hydroxyeicosatetraenoic acid (20-HETE) metabolism in coronary endothelial cells. Journal of Biological Chemistry. 2004; 279:2648-2656. [PubMed: 14612451]

60. Moreno JJ. New aspects of the role of hydroxyeico-satetraenoic acids in cell growth and cancer development. Biochemical Pharmacology. 2009; 77:1-10. [PubMed: 18761324]

61. Ayajiki K, Fujioka H, Toda N, Okada S, Minamiyama Y, Imaoka S, et al. Mediation of arachidonic acid metabolite(s) produced by endothelial cytochrome P-450 3A4 in monkey arterial relaxation. Hypertension Research. 2003; 26:237-243. [PubMed: 12675279]

62. Stark K, Dostalek M, Guengerich FP. Expression and purification of orphan cytochrome P450 4X1 and oxidation of anandamide. FEBS Journal. 2008; 275:3706-3717. [PubMed: 18549450]

63. Chuang SS, Helvig C, Taimi M, Ramshaw HA, Collop AH, Amad M, et al. CYP2U1, a novel human thymus- and brain-specific cytochrome P450, catalyzes omega-and (omega-1)hydroxylation of fatty acids. Journal of Biological Chemistry. 2004; 279:6305-6314. [PubMed: 14660610]

64. Yang W, Holmes BB, Gopal VR, Kishore RV, Sangras B, Yi XY, et al. Characterization of 14,15epoxyei-cosatrienoyl-sulfonamides as 14,15-epoxyeicosatrienoic acid agonists: Use for studies of metabolism and ligand binding. Journal of Pharmacology and Experimental Therapeutics. 2007; 321:1023-1031. [PubMed: 17327488]

65. Chen Y, Falck JR, Manthati VL, Jat JL, Campbell WB. 20-Iodo-14,15-epoxyeicosa-8(Z)-enoyl-3azidophe-nylsulfonamide: Photoaffinity labeling of a 14,15-epoxyeicosatrienoic acid receptor. Biochemistry. 2011; 50:3840-3848. [PubMed: 21469660]

66. Spector AA. Arachidonic acid cytochrome P450 epoxygenase pathway. Journal of Lipid Research. 2009; 50(Suppl):S52-56. [PubMed: 18952572]

67. Karara A, Wei S, Spady D, Swift L, Capdevila JH, Falck JR. Arachidonic acid epoxygenase: Structural characterization and quantification of epoxyeicosatrienoates in plasma. Biochemical and Biophysical Research Communications. 1992; 182:1320-1325. [PubMed: 1540175]

68. Spector AA, Fang X, Snyder GD, Weintraub NL. Epoxyeicosatrienoic acids (EETs): Metabolism and biochemical function. Progress in Lipid Research. 2004; 43:55-90. [PubMed: 14636671]

69. Widstrom RL, Norris AW, Van Der Veer J, Spector AA. Fatty acid-binding proteins inhibit hydration of epoxyeicosatrienoic acids by soluble epoxide hydrolase. Biochemistry. 2003; 42:11762-11767. [PubMed: 14529287]

70. Liu Y, Zhang Y, Schmelzer K, Lee TS, Fang X, Zhu Y, et al. The antiinflammatory effect of laminar flow: The role of PPARgamma, epoxyeicosatrienoic acids, and soluble epoxide hydrolase. 
Proceedings of the National Academy of Sciences of the United States of America. 2005; 102:16747-16752. [PubMed: 16267130]

71. Deng Y, Theken KN, Lee CR. Cytochrome P450 epoxygenases, soluble epoxide hydrolase, and the regulation of cardiovascular inflammation. Journal of Molecular and Cellular Cardiology. 2010; 48:331-341. [PubMed: 19891972]

72. Cowart LA, Wei S, Hsu MH, Johnson EF, Krishna MU, Falck JR, et al. The CYP4A isoforms hydroxylate epoxyeicosatrienoic acids to form high affinity peroxisome proliferator-activated receptor ligands. Journal of Biological Chemistry. 2002; 277:35105-35112. [PubMed: 12124379]

73. Fang X, Hu S, Watanabe T, Weintraub NL, Snyder GD, Yao J, et al. Activation of peroxisome proliferator-activated receptor alpha by substituted urea-derived soluble epoxide hydrolase inhibitors. Journal of Pharmacology and Experimental Therapeutics. 2005; 314:260-270. [PubMed: 15798002]

74. Fang X, Hu S, Xu B, Snyder GD, Harmon S, Yao J, et al. 14,15-Dihydroxyeicosatrienoic acid activates peroxisome proliferator-activated receptor-alpha. American Journal of Physiology Heart and Circulatory Physiology. 2006; 290:H55-63. [PubMed: 16113065]

75. Folkman J. Angiogenesis: An organizing principle for drug discovery? Nature Reviews Drug Discovery. 2007; 6:273-286.

76. Hafner C, Reichle A, Vogt T. New indications for established drugs: combined tumor-stromatargeted cancer therapy with PPARgamma agonists, COX-2 inhibitors, mTOR antagonists and metronomic chemotherapy. Current Cancer Drug Targets. 2005; 5:393-419. [PubMed: 16178816]

77. Balkwill F, Mantovani A. Cancer and inflammation: Implications for pharmacology and therapeutics. Clinical Pharmacology and Therapeutics. 2010; 87:401-406. [PubMed: 20200512]

78. Coussens LM, Werb Z. Inflammation and cancer. Nature. 2002; 420:860-867. [PubMed: 12490959]

79. Folkman J. What is the evidence that tumors are angiogenesis-dependent? Journal of the National Cancer Institute. 1990; 82:4-6. [PubMed: 1688381]

80. McAllister SS, Weinberg RA. Tumor-host interactions: A far-reaching relationship. Journal of Clinical Oncology. 2010; 28:4022-4028. [PubMed: 20644094]

81. Panigrahy D, Huang S, Kieran MW, Kaipainen A. PPARgamma as a therapeutic target for tumor angiogenesis and metastasis. Cancer Biology \& Therapy. 2005; 4:687-693. [PubMed: 16082179]

82. Bhowmick NA, Neilson EG, Moses HL. Stromal fibroblasts in cancer initiation and progression. Nature. 2004; 432:332-337. [PubMed: 15549095]

83. Folkman J. Tumor angiogenesis: Therapeutic implications. The New England Journal of Medicine. 1971; 285:1182-1186. [PubMed: 4938153]

84. Orimo A, Gupta PB, Sgroi DC, Arenzana-Seisdedos F, Delaunay T, Naeem R, et al. Stromal fibroblasts present in invasive human breast carcinomas promote tumor growth and angiogenesis through elevated SDF-1/CXCL12 secretion. Cell. 2005; 121:335-348. [PubMed: 15882617]

85. Joyce JA, Pollard JW. Microenvironmental regulation of metastasis. Nature Reviews Cancer. 2009; 9:239-252.

86. Lin EY, Pollard JW. Role of infiltrated leucocytes in tumour growth and spread. British Journal of Cancer. 2004; 90:2053-2058. [PubMed: 15164120]

87. de Visser KE, Eichten A, Coussens LM. Paradoxical roles of the immune system during cancer development. Nature Reviews Cancer. 2006; 6:24-37.

88. Zhang L, Conejo-Garcia JR, Katsaros D, Gimotty PA, Massobrio M, Regnani G, et al. Intratumoral T cells, recurrence, and survival in epithelial ovarian cancer. The New England Journal of Medicine. 2003; 348:203-213. [PubMed: 12529460]

89. Clevers H. At the crossroads of inflammation and cancer. Cell. 2004; 118:671-674. [PubMed: 15369667]

90. Aggarwal BB, Shishodia S, Sandur SK, Pandey MK, Sethi G. Inflammation and cancer: How hot is the link? Biochemical Pharmacology. 2006; 72:1605-1621. [PubMed: 16889756]

91. Seitz CS, Lin Q, Deng H, Khavari PA. Alterations in NF-kappaB function in transgenic epithelial tissue demonstrate a growth inhibitory role for NF-kappaB. Proceedings of the National Academy of Sciences of the United States of America. 1998; 95:2307-2312. [PubMed: 9482881] 
92. Dajee M, Lazarov M, Zhang JY, Cai T, Green CL, Russell AJ, et al. NF-kappaB blockade and oncogenic Ras trigger invasive human epidermal neoplasia. Nature. 2003; 421:639-643. [PubMed: 12571598]

93. Karin M. NF-kappaB as a critical link between inflammation and cancer. Cold Spring Harbor Perspectives in Biology. 2009; 1:a000141. [PubMed: 20066113]

94. Kaipainen A, Kieran MW, Huang S, Butterfield C, Bielenberg D, Mostoslavsky G, et al. PPARalpha deficiency in inflammatory cells suppresses tumor growth. PLoS One. 2007; 2:e260. [PubMed: 17327920]

95. Panigrahy D, Kaipainen A, Kieran MW, Huang S. PPARs: A double-edged sword in cancer therapy? PPAR Research. 2008; 2008:350351. [PubMed: 19590598]

96. Ono M. Molecular links between tumor angiogenesis and inflammation: Inflammatory stimuli of macrophages and cancer cells as targets for therapeutic strategy. Cancer Science. 2008; 99:15011506. [PubMed: 18754859]

97. Salcedo R, Zhang X, Young HA, Michael N, Wasserman K, Ma WH, et al. Angiogenic effects of prostaglandin E2 are mediated by up-regulation of CXCR4 on human microvascular endothelial cells. Blood. 2003; 102:1966-1977. [PubMed: 12791666]

98. Freedman RS, Wang E, Voiculescu S, Patenia R, Bassett RL Jr, Deavers M, et al. Comparative analysis of peritoneum and tumor eicosanoids and pathways in advanced ovarian cancer. Clinical Cancer Research. 2007; 13:5736-5744. [PubMed: 17908963]

99. Ishizuka T, Cheng J, Singh H, Vitto MD, Manthati VL, Falck JR, et al. 20-

Hydroxyeicosatetraenoic acid stimulates nuclear factor-kappaB activation and the production of inflammatory cytokines in human endothelial cells. Journal of Pharmacology and Experimental Therapeutics. 2008; 324:103-110. [PubMed: 17947496]

100. Guo AM, Arbab AS, Falck JR, Chen P, Edwards PA, Roman RJ, et al. Activation of vascular endothelial growth factor through reactive oxygen species mediates 20 -hydroxyeicosatetraenoic acid-induced endothelial cell proliferation. Journal of Pharmacology and Experimental Therapeutics. 2007; 321:18-27. [PubMed: 17210799]

101. Dhanasekaran A, Bodiga S, Gruenloh S, Gao Y, Dunn L, Falck JR, et al. 20-HETE increases survival and decreases apoptosis in pulmonary arteries and pulmonary artery endothelial cells. American Journal of Physiology Heart and Circulatory Physiology. 2009; 296:H777-786. [PubMed: 19136601]

102. Chen P, Guo M, Wygle D, Edwards PA, Falck JR, Roman RJ, et al. Inhibitors of cytochrome P450 4A suppress angiogenic responses. American Journal of Pathology. 2005; 166:615-624. [PubMed: 15681843]

103. Ljubimov AV, Grant MB. P450 in the angiogenesis affair: The unusual suspect. American Journal of Pathology. 2005; 166:341-344. [PubMed: 15681818]

104. Amaral SL, Maier KG, Schippers DN, Roman RJ, Greene AS. CYP4A metabolites of arachidonic acid and VEGF are mediators of skeletal muscle angiogenesis. American Journal of Physiology Heart and Circulatory Physiology. 2003; 284:H1528-1535. [PubMed: 12521947]

105. Sa G, Murugesan G, Jaye M, Ivashchenko Y, Fox PL. Activation of cytosolic phospholipase A2 by basic fibroblast growth factor via a p42 mitogen-activated protein kinase-dependent phosphorylation pathway in endothelial cells. Journal of Biological Chemistry. 1995; 270:23602366. [PubMed: 7836470]

106. Jiang M, Mezentsev A, Kemp R, Byun K, Falck JR, Miano JM, et al. Smooth muscle-specific expression of CYP4A1 induces endothelial sprouting in renal arterial microvessels. Circulation Research. 2004; 94:167-174. [PubMed: 14670847]

107. Miyata N, Taniguchi K, Seki T, Ishimoto T, Sato-Watanabe M, Yasuda Y, et al. HET0016, a potent and selective inhibitor of 20-HETE synthesizing enzyme. British Journal of Pharmacology. 2001; 133:325-329. [PubMed: 11375247]

108. Guo M, Roman RJ, Falck JR, Edwards PA, Scicli AG. Human U251 glioma cell proliferation is suppressed by HET0016 [ $N$-hydroxy- $N$-(4-butyl-2-methylphenyl)formamidine], a selective inhibitor of CYP4A. Journal of Pharmacology and Experimental Therapeutics. 2005; 315:526533. [PubMed: 16081682] 
109. Jacobs ER, Zhu D, Gruenloh S, Lopez B, Medhora M. VEGF-induced relaxation of pulmonary arteries is mediated by endothelial cytochrome P-450 hydroxylase. American Journal of Physiology Lung Cellular and Molecular Physiology. 2006; 291:L369-377. [PubMed: 16679379]

110. Guo AM, Sheng J, Scicli GM, Arbab AS, Lehman NL, Edwards PA, et al. Expression of CYP4A1 in U251 human glioma cell induces hyperproliferative phenotype in vitro and rapidly growing tumors in vivo. Journal of Pharmacology and Experimental Therapeutics. 2008; 327:1019. [PubMed: 18591218]

111. Guo M, Roman RJ, Fenstermacher JD, Brown SL, Falck JR, Arbab AS, et al. 9L gliosarcoma cell proliferation and tumor growth in rats are suppressed by $N$-hydroxy- $N$-(4-butyl-2-methylphenol) formamidine (HET0016), a selective inhibitor of CYP4A. Journal of Pharmacology and Experimental Therapeutics. 2006; 317:97-108. [PubMed: 16352703]

112. Alexanian A, Rufanova VA, Miller B, Flasch A, Roman RJ, Sorokin A. Down-regulation of 20HETE synthesis and signaling inhibits renal adenocarcinoma cell proliferation and tumor growth. Anticancer Research. 2009; 29:3819-3824. [PubMed: 19846914]

113. Yu W, Chen L, Yang YQ, Falck JR, Guo AM, Li Y, et al. Cytochrome P450 w-hydroxylase promotes angiogenesis and metastasis by upregulation of VEGF and MMP-9 in non-small cell lung cancer. Cancer Chemotherapy and Pharmacology. 2011; 68:619-629. [PubMed: 21120482]

114. Nithipatikom K, Isbell MA, See WA, Campbell WB. Elevated 12- and 20hydroxyeicosatetraenoic acid in urine of patients with prostatic diseases. Cancer Letters. 2006; 233:219-225. [PubMed: 15882928]

115. Zhang C, Harder DR. Cerebral capillary endothelial cell mitogenesis and morphogenesis induced by astrocytic epoxyeicosatrienoic Acid. Stroke. 2002; 33:2957-2964. [PubMed: 12468797]

116. Medhora M, Daniels J, Mundey K, Fisslthaler B, Busse R, Jacobs ER, et al. Epoxygenase-driven angiogenesis in human lung microvascular endothelial cells. American Journal of Physiology Heart and Circulatory Physiology. 2003; 284:H215-224. [PubMed: 12388259]

117. Ausprunk DH, Folkman J. Migration and proliferation of endothelial cells in preformed and newly formed blood vessels during tumor angiogenesis. Microvascular Research. 1977; 14:5361. [PubMed: 895546]

118. Ribatti D, Vacca A, Roncali L, Dammacco F. The chick embryo chorioallantoic membrane as a model for in vivo research on antiangiogenesis. Current Pharmacology Biotechnology. 2000; 1:73-82.

119. Michaelis UR, Fisslthaler B, Medhora M, Harder D, Fleming I, Busse R. Cytochrome P450 2C9derived epoxyeicosatrienoic acids induce angiogenesis via cross-talk with the epidermal growth factor receptor (EGFR). The FASEB Journal. 2003; 17:770-772.

120. Yan G, Chen S, You B, Sun J. Activation of sphingosine kinase-1 mediates induction of endothelial cell proliferation and angiogenesis by epoxyeicosatrienoic acids. Cardiovascular Research. 2008; 78:308-314. [PubMed: 18192241]

121. Zhang B, Cao H, Rao GN. Fibroblast growth factor-2 is a downstream mediator of phosphatidylinositol 3-kinase-Akt signaling in 14,15-epoxyeicosatrienoic acid-induced angiogenesis. Journal of Biological Chemistry. 2006; 281:905-914. [PubMed: 16286479]

122. Cheranov SY, Karpurapu M, Wang D, Zhang B, Venema RC, Rao GN. An essential role for SRC-activated STAT-3 in 14,15-EET-induced VEGF expression and angiogenesis. Blood. 2008; 111:5581-5591. [PubMed: 18408167]

123. Yang S, Lin L, Chen JX, Lee CR, Seubert JM, Wang Y, et al. Cytochrome P-450 epoxygenases protect endothelial cells from apoptosis induced by tumor necrosis factor-alpha via MAPK and PI3K/Akt signaling pathways. American Journal of Physiology Heart and Circulatory Physiology. 2007; 293:H142-151. [PubMed: 17322420]

124. Tsuzuki Y, Fukumura D, Oosthuyse B, Koike C, Carmeliet P, Jain RK. Vascular endothelial growth factor (VEGF) modulation by targeting hypoxia-inducible factor-1alpha $\rightarrow$ hypoxia response element $\rightarrow$ VEGF cascade differentially regulates vascular response and growth rate in tumors. Cancer Research. 2000; 60:6248-6252. [PubMed: 11103778] 
125. Michaelis UR, Fisslthaler B, Barbosa-Sicard E, Falck JR, Fleming I, Busse R. Cytochrome P450 epoxygenases $2 \mathrm{C} 8$ and $2 \mathrm{C} 9$ are implicated in hypoxia-induced endothelial cell migration and angiogenesis. Journal of Cell Science. 2005; 118:5489-5498. [PubMed: 16291720]

126. Earley S, Pastuszyn A, Walker BR. Cytochrome p- 450 epoxygenase products contribute to attenuated vasocon-striction after chronic hypoxia. American Journal of Physiology Heart and Circulatory Physiology. 2003; 285:H127-136. [PubMed: 12623785]

127. Suzuki S, Oguro A, Osada-Oka M, Funae Y, Imaoka S. Epoxyeicosatrienoic acids and/or their metabolites promote hypoxic response of cells. Journal of Pharmacological Sciences. 2008; 108:79-88. [PubMed: 18776712]

128. Webler AC, Michaelis UR, Popp R, Barbosa-Sicard E, Murugan A, Falck JR, et al. Epoxyeicosatrienoic acids are part of the VEGF-activated signaling cascade leading to angiogenesis. American Journal of Physiology Cell Physiology. 2008; 295:C1292-1301. [PubMed: 18787075]

129. Yang S, Wei S, Pozzi A, Capdevila JH. The arachidonic acid epoxygenase is a component of the signaling mechanisms responsible for VEGF-stimulated angiogenesis. Archives of Biochemistry and Biophysics. 2009; 489:82-91. [PubMed: 19464254]

130. Schmelzer KR, Kubala L, Newman JW, Kim IH, Eiserich JP, Hammock BD. Soluble epoxide hydrolase is a therapeutic target for acute inflammation. Proceedings of the National Academy of Sciences of the United States of America. 2005; 102:9772-9777. [PubMed: 15994227]

131. Schmelzer KR, Inceoglu B, Kubala L, Kim IH, Jinks SL, Eiserich JP, et al. Enhancement of antinociception by coadministration of nonsteroidal anti-inflammatory drugs and soluble epoxide hydrolase inhibitors. Proceedings of the National Academy of Sciences of the United States of America. 2006; 103:13646-13651. [PubMed: 16950874]

132. Norwood S, Liao J, Hammock BD, Yang GY. Epoxyeicosatrienoic acids and soluble epoxide hydrolase: Potential therapeutic targets for inflammation and its induced carcinogenesis. American Journal of Translation Research. 2010; 2:447-457.

133. Vainio P, Gupta S, Ketola K, Mirtti T, Mpindi JP, Kohonen P, et al. Arachidonic acid pathway members PLA2G7, HPGD, EPHX2, and CYP4F8 identified as putative novel therapeutic targets in prostate cancer. American Journal of Pathology. 2011; 178:525-536. [PubMed: 21281786]

134. Harris RC, Homma T, Jacobson HR, Capdevila J. Epoxyeicosatrienoic acids activate $\mathrm{Na}^{+} / \mathrm{H}^{+}$ exchange and are mitogenic in cultured rat glomerular mesangial cells. Journal of Cellular Physiology. 1990; 144:429-437. [PubMed: 2167900]

135. Sellmayer A, Uedelhoven WM, Weber PC, Bonventre JV. Endogenous non-cyclooxygenase metabolites of arachidonic acid modulate growth and mRNA levels of immediate-early response genes in rat mesangial cells. Journal of Biological Chemistry. 1991; 266:3800-3807. [PubMed: 1899867]

136. Jiang JG, Chen CL, Card JW, Yang S, Chen JX, Fu XN, et al. Cytochrome P450 2J2 promotes the neoplastic phenotype of carcinoma cells and is up-regulated in human tumors. Cancer Research. 2005; 65:4707-4715. [PubMed: 15930289]

137. Chen C, Wei X, Rao X, Wu J, Yang S, Chen F, et al. Cytochrome P450 2J2 is highly expressed in hematologic malignant diseases and promotes tumor cell growth. Journal of Pharmacology and Experimental Therapeutics. 2011; 336:344-355. [PubMed: 21030485]

138. Cheng LM, Jiang JG, Sun ZY, Chen C, Dackor RT, Zeldin DC, et al. The epoxyeicosatrienoic acid-stimulated phosphorylation of EGF-R involves the activation of metalloproteinases and the release of HB-EGF in cancer cells. Acta Pharmacologica Sinica. 2010; 31:211-218. [PubMed: 20139904]

139. Chen C, Li G, Liao W, Wu J, Liu L, Ma D, et al. Selective inhibitors of CYP2J2 related to terfenadine exhibit strong activity against human cancers in vitro and in vivo. Journal of Pharmacology and Experimental Therapeutics. 2009; 329:908-918. [PubMed: 19289568]

140. Panigrahy D, Kaipainen A, Huang S, Butterfield CE, Barnes CM, Fannon M, et al. PPARalpha agonist fenofibrate suppresses tumor growth through direct and indirect angiogenesis inhibition. Proceedings of the National Academy of Sciences of the United States of America. 2008; 105:985-990. [PubMed: 18199835] 
141. Hammock BD, Ota K. Differential induction of cytosolic epoxide hydrolase, microsomal epoxide hydrolase, and glutathione S-transferase activities. Toxicology and Applied Pharmacology. 1983; 71:254-265. [PubMed: 6636190]

142. Tanaka H, Kamita SG, Wolf NM, Harris TR, Wu Z, Morisseau C, et al. Transcriptional regulation of the human soluble epoxide hydrolase gene EPHX2. Biochimica et Biophysica Acta. 2008; 1779:17-27. [PubMed: 18078836]

143. Wray J, Bishop-Bailey D. Epoxygenases and peroxisome proliferator-activated receptors in mammalian vascular biology. Experimental Physiology. 2008; 93:148-154. [PubMed: 17872966]

144. Ng VY, Huang Y, Reddy LM, Falck JR, Lin ET, Kroetz DL. Cytochrome P450 eicosanoids are activators of peroxisome proliferator-activated receptor alpha. Drug Metabolism and Disposition. 2007; 35:1126-1134. [PubMed: 17431031]

145. Wray JA, Sugden MC, Zeldin DC, Greenwood GK, Samsuddin S, Miller-Degraff L, et al. The epoxygenases CYP2J2 activates the nuclear receptor PPARalpha in vitro and in vivo. PLoS One. 2009; 4:e7421. [PubMed: 19823578]

146. Kieran MW. DFCI Protocol 04343. 5 drug metronomic chemotherapy protocol for children with incurable tumors-Clinical trial ongoing. 2010

147. Zagorac D, Jakovcevic D, Gebremedhin D, Harder DR. Antiangiogenic effect of inhibitors of cytochrome $\mathrm{P} 450$ on rats with glioblastoma multiforme. Journal of Cerebral Blood Flow and Metabolism. 2008; 28:1431-1439. [PubMed: 18414496]

148. Nithipatikom K, Brody DM, Tang AT, Manthati VL, Falck JR, Williams CL, et al. Inhibition of carcinoma cell motility by epoxyeicosatrienoic acid (EET) antagonists. Cancer Science. 2010; 101:2629-2636. [PubMed: 20804500]

149. Mitra R, Guo Z, Milani M, Mesaros C, Rodriguez M, Nguyen J, et al. CYP3A4 mediates growth of estrogen receptor-positive breast cancer cells in part by inducing nuclear translocation of phospho-Stat3 through biosynthesis of ( \pm )-14,15-epoxyeicosatrienoic acid (EET). Journal of Biological Chemistry. 2011; 286:17543-17559. [PubMed: 21402692]

150. Oguro A, Sakamoto K, Funae Y, Imaoka S. Overexpression of CYP3A4, but not CYP2D6, promotes hypoxic response and cell growth of Hep3B cells. Drug Metabolism Pharmacokinetics. 2011; 26:407-415. [PubMed: 21566342]

151. Schmelzle M, Dizdar L, Matthaei H, Baldus SE, Wolters J, Lindenlauf N, et al. Esophageal cancer proliferation is mediated by cytochrome P450 2C9 (CYP2C9). Prostaglandins \& Other Lipid Mediators. 2011; 94:25-33. [PubMed: 21167292]

152. Guengerich FP, Turvy CG. Comparison of levels of several human microsomal cytochrome P-450 enzymes and epoxide hydrolase in normal and disease states using immuno-chemical analysis of surgical liver samples. Journal of Pharmacology and Experimental Therapeutics. 1991; 256:1189-1194. [PubMed: 2005581]

153. Enayetallah AE, French RA, Grant DF. Distribution of soluble epoxide hydrolase, cytochrome P450 2C8, 2C9 and 2J2 in human malignant neoplasms. Journal of Molecular Histology. 2006; 37:133-141. [PubMed: 16957870]

154. Leclerc J, Tournel G, Courcot-Ngoubo Ngangue E, Pottier N, Lafitte JJ, Jaillard S, et al. Profiling gene expression of whole cytochrome P450 superfamily in human bronchial and peripheral lung tissues: Differential expression in non-small cell lung cancers. Biochimie. 2010; 92:292-306. [PubMed: 20034539]

155. Murray GI, Patimalla S, Stewart KN, Miller ID, Heys SD. Profiling the expression of cytochrome P450 in breast cancer. Histopathology. 2010; 57:202-211. [PubMed: 20716162]

156. Goodman AI, Choudhury M, da Silva JL, Schwartzman ML, Abraham NG. Overexpression of the heme oxygenase gene in renal cell carcinoma. Proceedings of the Society for Experimental Biology and Medicine. 1997; 214:54-61. [PubMed: 9012361]

157. Yang MD, Wu CC, Chiou SH, Chiu CF, Lin TY, Chiang IP, et al. Reduction of dihydrodiol dehydrogenase expression in resected hepatocellular carcinoma. Oncology Reports. 2003; 10:271-276. [PubMed: 12579257] 
158. Roques M, Bagrel D, Magdalou J, Siest G. Expression of arylhydrocarbon hydroxylase, epoxide hydrolases, glutathione S-transferase and UDP-glucuronosyltransferases in H5-6 hepatoma cells. General Pharmacology. 1991; 22:677-684. [PubMed: 1936901]

159. Thomassen M, Tan Q, Kruse TA. Gene expression meta-analysis identifies chromosomal regions and candidate genes involved in breast cancer metastasis. Breast Cancer Research and Treatment. 2009; 113:239-249. [PubMed: 18293085]

160. Rahman A, Korzekwa KR, Grogan J, Gonzalez FJ, Harris JW. Selective biotransformation of taxol to 6 alpha-hydroxytaxol by human cytochrome P450 2C8. Cancer Research. 1994; 54:5543-5546. [PubMed: 7923194]

161. Dai D, Zeldin DC, Blaisdell JA, Chanas B, Coulter SJ, Ghanayem BI, et al. Polymorphisms in human CYP2C8 decrease metabolism of the anticancer drug paclitaxel and arachidonic acid. Pharmacogenetics. 2001; 11:597-607. [PubMed: 11668219]

162. Jernstrom H, Bageman E, Rose C, Jonsson PE, Ingvar C. CYP2C8 and CYP2C9 polymorphisms in relation to tumour characteristics and early breast cancer related events among 652 breast cancer patients. British Journal of Cancer. 2009; 101:1817-1823. [PubMed: 19935798]

163. Isomura Y, Yamaji Y, Ohta M, Seto M, Asaoka Y, Tanaka Y, et al. A genetic polymorphism of CYP2C19 is associated with susceptibility to biliary tract cancer. Journal of Gastroenterology. 2010; 45:1045-1052. [PubMed: 20549256]

164. Fornage M, Boerwinkle E, Doris PA, Jacobs D, Liu K, Wong ND. Polymorphism of the soluble epoxide hydrolase is associated with coronary artery calcification in African-American subjects: The Coronary Artery Risk Development in Young Adults (CARDIA) Study. Circulation. 2004; 109:335-339. [PubMed: 14732757]

165. Lee CR, North KE, Bray MS, Fornage M, Seubert JM, Newman JW, et al. Genetic variation in soluble epoxide hydrolase (EPHX2) and risk of coronary heart disease: The Atherosclerosis Risk in Communities (ARIC) Study. Human Molecular Genetics. 2006; 15:1640-1649. [PubMed: 16595607]

166. Breyer RM, Bagdassarian CK, Myers SA, Breyer MD. Prostanoid receptors: Subtypes and signaling. Annual Review of Pharmacology and Toxicology. 2001; 41:661-690.

\section{Abbreviations}

$\begin{array}{ll}\text { CYP and P450 } & \text { Cytochrome P450 } \\ \text { COX } & \text { Cyclooxygenase } \\ \text { LOX } & \text { Lipoxygenase } \\ \text { EET } & \text { Epoxyeicosatrienoic acid } \\ \text { HETE } & \text { Hydroxyeicosatetraenoic acid } \\ \text { SEH } & \text { Soluble epoxide hydrolase } \\ \text { DHET } & \text { Dihydroxyeicosatrienoic acid } \\ \text { 14,15-EEZE } & \text { 14,15-Epoxyeicosa-5(Z)-enoic acid } \\ \text { PGE }_{2} & \text { Prostaglandin } \mathrm{E}_{2} \\ \text { LTB } & \text { Leukotriene } \mathrm{B}_{4} \\ \text { VEGF } & \text { Vascular endothelial growth factor } \\ \text { FGF-2 } & \text { Fibroblast growth factor-2 } \\ \text { TGF- } \boldsymbol{\beta} & \text { Transforming growth factor beta } \\ \text { TNF-a } & \text { Tumor necrosis factor-alpha } \\ \text { IL-1 } & \text { Interleukin-1 } \\ \text { EGF } & \text { Epidermal growth factor }\end{array}$




$\begin{array}{ll}\text { EGFR } & \text { Epidermal growth factor receptor } \\ \text { MAPK/ERK } & \text { Mitogen-activated protein kinase/Extracellular signal-regulated kinase } \\ \text { ROS } & \text { Reactive oxygen species } \\ \text { NF-KB } & \text { Nuclear factor-kappaB } \\ \text { ICAM } & \text { Intracellular adhesion molecule } \\ \text { VCAM-1 } & \text { Vascular cell adhesion molecule-1 } \\ \text { HIF-1a } & \text { Hypoxia-inducible factor-1a } \\ \text { NO } & \text { Nitric oxide } \\ \text { eNOS } & \text { Endothelial nitric oxide synthase } \\ \text { iNOS } & \text { Inducible nitric oxide synthase } \\ \text { PI3K/Akt } & \text { Phospatidylinositol-3-kinase/Akt } \\ \text { PPAR } & \text { Peroxisome proliferator-activated receptor } \\ \text { RXR } & \text { Retinoid X receptor } \\ \text { PPRE } & \text { Peroxisome proliferator response element } \\ \text { PSA } & \text { Prostate-specific antigen } \\ \text { MMP-9 } & \text { Metalloproteinase-9 } \\ \text { CAM } & \text { Chorioallantoic membrane } \\ \text { SK1 } & \text { Sphingosine kinase-1 } \\ \text { AUDA-BE } & \text { 12-(3-Adamantan-1-yl-ureido)-dodecanoic acid butyl ester } \\ \text { NSAIDs } & \text { Non-steroidal anti-inflammatory drugs } \\ \text { HB-EGF } & \text { Heparin-binding epidermal growth factor-like growth factor } \\ \text { EPHX2 } & \text { Epoxide hydrolase 2 } \\ \text { SCC } & \text { Squamous cell carcinoma }\end{array}$



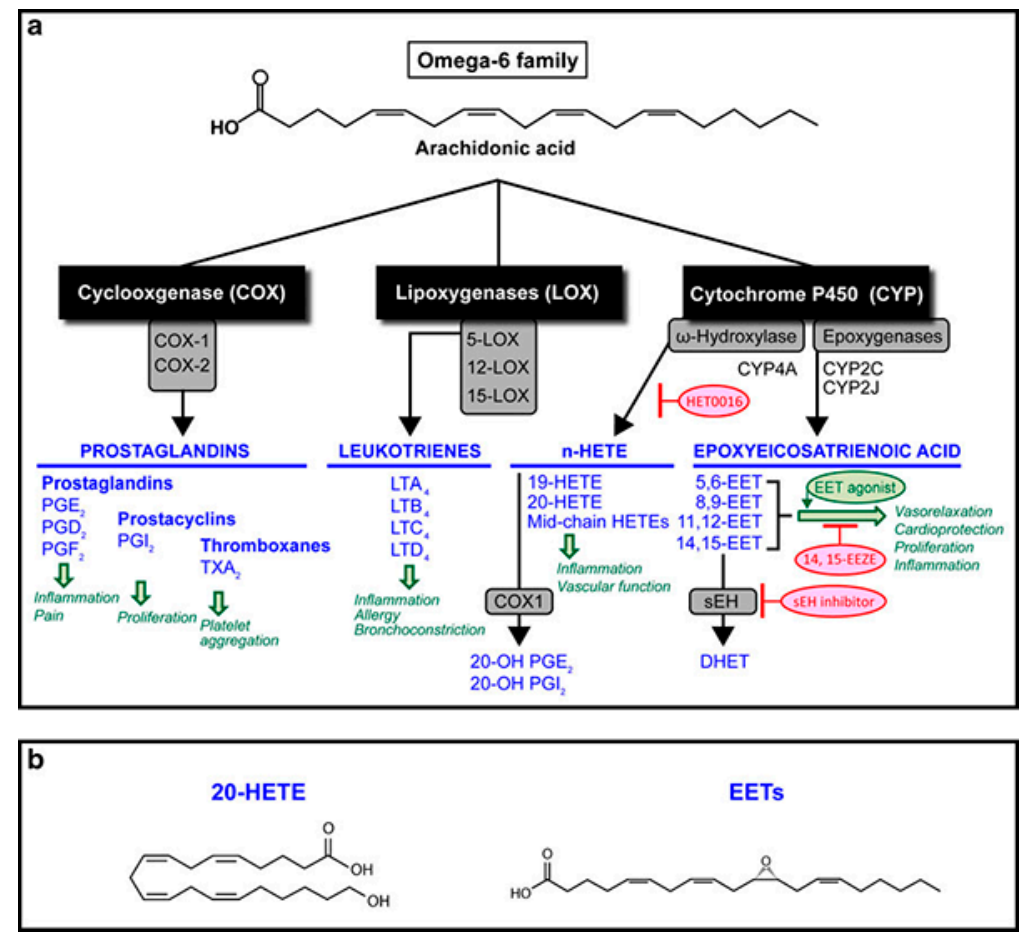

Fig. 1.

Bioactive eicosanoids derived from the arachidonic acid cascade. Arachidonic acid is metabolized by three pathways - the cyclooxygenase $(C O X)$, lipoxygenase $(L O X)$, and cytochrome P450 (CYP) pathways. Schematic overview of major mediators and their metabolites (blue), enzymes (black, boxed), biological role (green), inhibitors (red ovals), and agonists (green ovals). HETE hydroxyei-cosatetraenoic acids, EETs epoxyeicosatrienoic acids, $C Y P$ cytochrome P450 enzymes. MSPPOH is a selective inhibitor of a subset of epoxygenases. HET0016 is a selective inhibitor of the $\omega$-hydroxlase CYP4A. The sEH inhibitor (soluble epoxide hydrolase inhibitors) increases EET levels and hence acts as agonist of the EET pathway. 14,15-EEZE is a putative EET receptor antagonist. $P G E_{2}$ prostaglandin $\mathrm{E}_{2}, P G I_{2}$ prostacyclin, $L T A_{4}$ leukotriene $\mathrm{A}_{4}, D H E T$ dihydroxyeicosatrienoic acid, 20-OH PGE 20-hydroxy prostaglandin $\mathrm{E}_{2}$ 


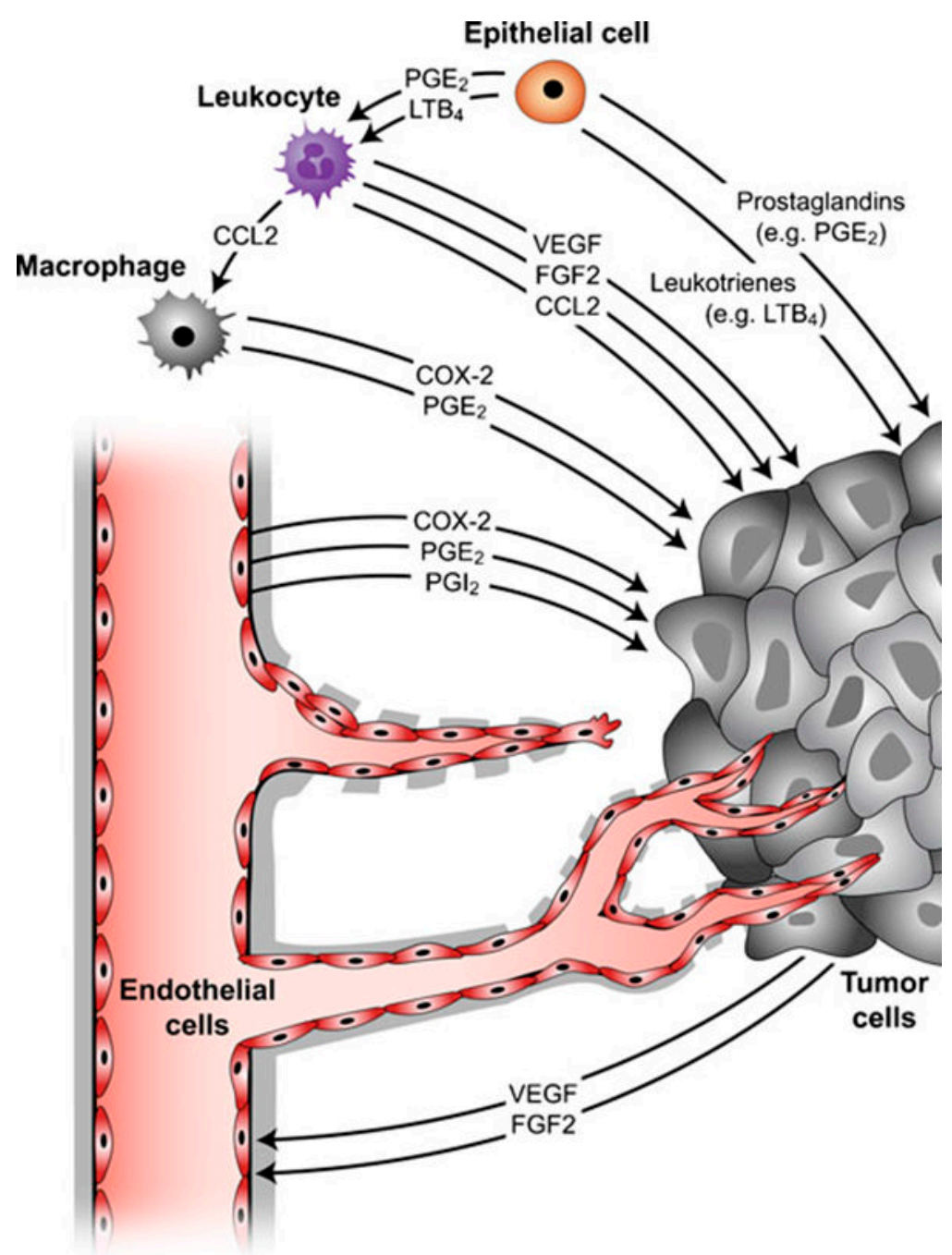

Fig. 2.

Eicosanoids in cancer and the tumor microenvironment. Lipid autacoids, such as $\mathrm{PGE}_{2}$ and $\mathrm{LTB}_{4}$, stimulate both epithelial cells and stromal cells to produce VEGF and FGF-2. These angiogenic growth factors induce $\mathrm{COX} 2$ and, in turn $\mathrm{PGE}_{2}$ and $\mathrm{PGI}_{2}$, in endothelial cells, creating an autocatalytic feedback loop. CCL2 (also known as monocyte chemotactic protein-1 or MCP-1) can stimulate macrophages to release COX2 and $\mathrm{PGE}_{2}$ 


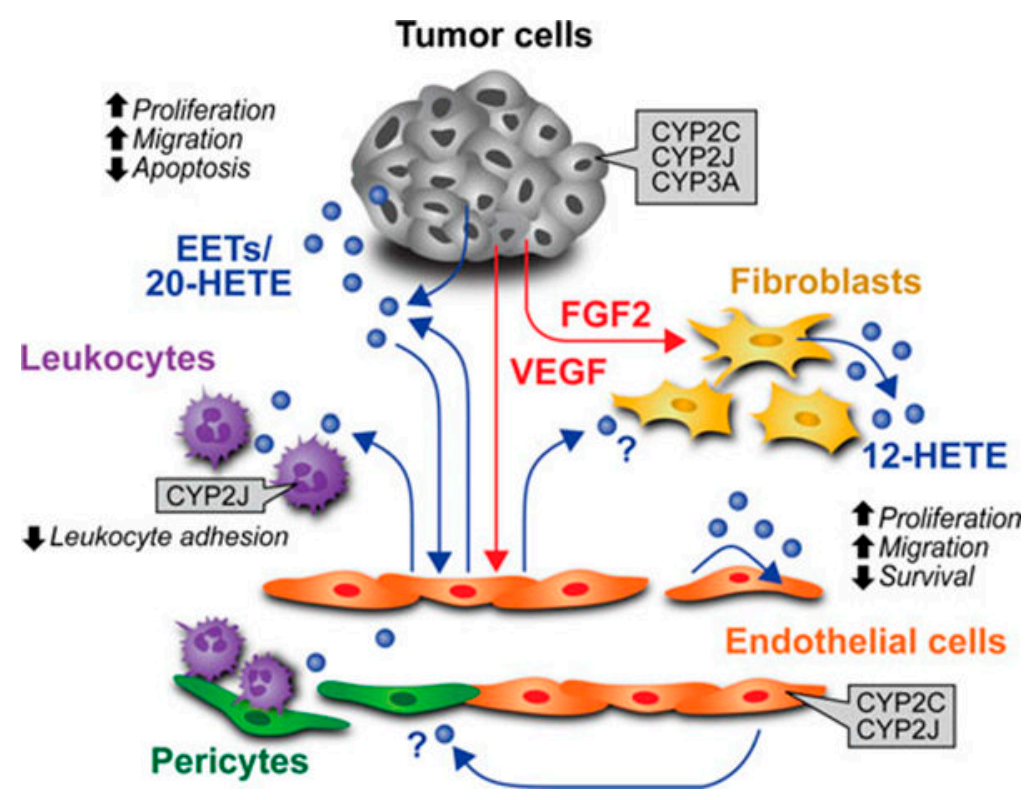

Fig. 3.

Cytochrome P450 epoxygenase expression in tumor cell compartments and their potential role in cell-cell communication in the tumor stroma. Tumor cells, endothelial cells, and leukocytes express cytochrome P450 ( $C Y P$ ) enzymes which can convert arachidonic acid to epoxyeicosatrienoic acids (EETS, blue circles) or 20-hydroxyeicosatetraenoic (20-HETE), establishing an autocatalytic loop 